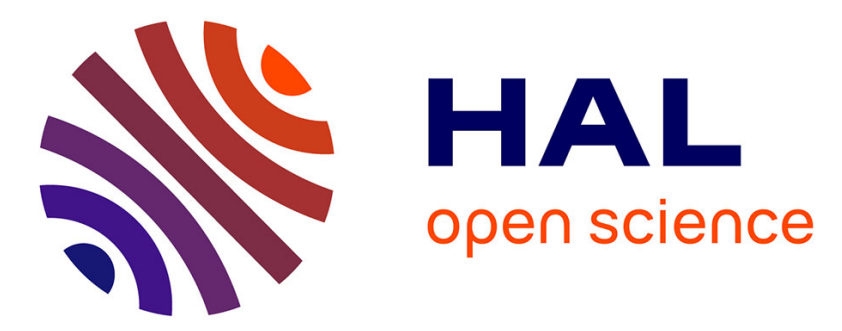

\title{
Stand-alone renewable power system scheduling for a green data center using integer linear programming
}

\author{
Marwa Haddad, Jean-Marc Nicod, Marie-Cécile Péra, Christophe Varnier
}

\section{To cite this version:}

Marwa Haddad, Jean-Marc Nicod, Marie-Cécile Péra, Christophe Varnier. Stand-alone renewable power system scheduling for a green data center using integer linear programming. Journal of Scheduling, 2021, 24 (5), pp.523 - 541. 10.1007/s10951-021-00700-y · hal-03455029

\section{HAL Id: hal-03455029 \\ https://hal.science/hal-03455029}

Submitted on 29 Nov 2021

HAL is a multi-disciplinary open access archive for the deposit and dissemination of scientific research documents, whether they are published or not. The documents may come from teaching and research institutions in France or abroad, or from public or private research centers.
L'archive ouverte pluridisciplinaire HAL, est destinée au dépôt et à la diffusion de documents scientifiques de niveau recherche, publiés ou non, émanant des établissements d'enseignement et de recherche français ou étrangers, des laboratoires publics ou privés. 


\title{
Stand-Alone Renewable Power System Scheduling for a Green Data-Center using Integer Linear Programming
}

\author{
Maroua Haddad · Jean-Marc Nicod · Marie-Cécile Péra · Christophe \\ Varnier
}

Received: January 2019

\begin{abstract}
Taking into account the spread of data centers around the world and their huge energy consumption, several researchers focused on task scheduling and resource allocation problem in order to minimize the energy consumed by the data center. Other initiatives focus on the implementation of green energy sources in order to minimize the consumption of fossil fuels and their emission of $\mathrm{CO} 2$. As part of the ANR DATAZERO project [34], several research teams aim at defining main concepts of a full green data center, only powered by renewable energies. To achieve this goal, it is mandatory to focus on the efficient management of an autonomous hybrid power system consisting of solar panels, wind turbines, batteries and fuel cell systems. The purpose of this work is not to show that a stand alone data center is economically viable but rather feasible. This paper proposes a set of models based on mixed integer linear programs able to manage the energy commitment to address the data center power demand. The approach takes the season and weather forecasts into account at the time of optimization.
\end{abstract}

Keywords Renewable energy, wind turbine, photovoltaic panel, hybrid energy storage, data center, integer linear program, optimization.

M. Haddad, J.-M. Nicod, and C. Varnier

FEMTO-ST Institute, Université Bourgogne Franche-Comté, CNRS/ENSMM, Besançon, France. E-mail: [marwa.haddad|jeanmarc.nicod|chirstophe.varnier]@femto-st.fr

M.-C. Péra FEMTO-ST Institute, Université Bourgogne FrancheComté, FCLAB/CNRS/UTBM, Belfort, France. E-mail: [mariececile.pera@femto-st.fr]

\section{Introduction}

The enormous growth of the Internet and the increase in the number of online services accessible to public have highlighted the cost imposed by the cloud in general and by data centers in particular in terms of energy consumption over the past few years. Nowadays, a typical data center includes hundreds of thousands of servers, cooling equipment, and substation transformers which contribute greatly in global warming as they deliver a huge quantity of $\mathrm{CO} 2$.

In this context, many green initiatives are being taken to make the use of data centers more virtuous in terms of their ecological footprint. One of these initiatives is the use of renewable energy sources (RES) in data center power system and even making sure that energy production is directly integrated into their own facilities. Thus, McGraw-Hill company completed a 14.1 $\mathrm{MW}$ solar panel installation to power its data center located in East Windsor, New Jersey [31]. Similarly, Apple has built a $40 M W$ solar field for its North Carolina data center [2]. Nevertheless, the intermittent nature of renewable energy sources (sun and wind) is driving these data centers to resell surplus energy and use conventional sources to provide continuous service. This economically viable energy policy is not entirely satisfying in terms of carbon footprint.

For this reason, the ANR DATAZERO project [34] adopts an original approach which consists in computing data center's resources provisioned with $100 \%$ renewable energy. The purpose of this project is to study the feasibility of a stand alone data center while limiting its carbon footprint. Designing and operating such a data center is however not trivial. There is a need to optimize the IT load to the energy availability, and 
conversely, to optimize the energy production to the incoming IT load. The sizing of the system in terms of IT and electrical components is also a huge challenge [17]. Thus, the ANR DATAZERO project is divided into two main decision modules: an IT decision module (ITDM) responsible for the management of the IT part (scheduling tasks, virtualization of servers, etc.) and a power decision module (PDM) responsible for the management of the renewable sources (source commitment, energy storage, etc.). The ambition of the project is to converge user needs with renewable energy production through a negotiation loop (NM) [7] as illustrated in Figure 1. Indeed, at each negotiation step, one asks to receive one or several energy profiles that can be delivered by the electrical part of the data center and able to be consumed by the IT part to satisfy a given level of computation for final clients. The negotiation continues bargaining with the two modules till achieving the convergence between the IT and electrical power profiles [38]. So, depending on the circumstances and on the period of the year, the level of energy available for the calculations may vary. The principle is that the sizing of both the IT and the electrical parts must allow a computation service in accordance with the quality of service announced in full autonomy thanks to short and long-term storage devices. These storage devices help smoothing the energy production available to supply the data center so that it can provide online services all day and all year long. However, the energy demand is not constant over time because client demand varies. So managing the use of storage in an appropriate way, with a view of satisfying a given computing demand, taking the intermittency of electrical power provided by the primary sources into account, is a major challenge. As suggested in [19], short-term and long-term storage are respectively done by using batteries and through the production of hydrogen with electrolyzers and the reverse generation of electricity is done with fuel cells.

Thus, this article presents, as part of the ANR DATAZERO project, an optimal management of a hybrid renewable energy system (HRES) consisting of solar panels, wind turbines, batteries and fuel cell systems with electrolyzers to supply a data center without exchange with the external electricity network. Depending on the quantity of renewable energy produced and the IT power demand over time, the storage sources must be managed. For instance, if the renewable production exceeds the data center's demand, the energy difference should be stored. Conversely, in case the client demand is higher than the renewable production, the storage devices should provide the energy difference.

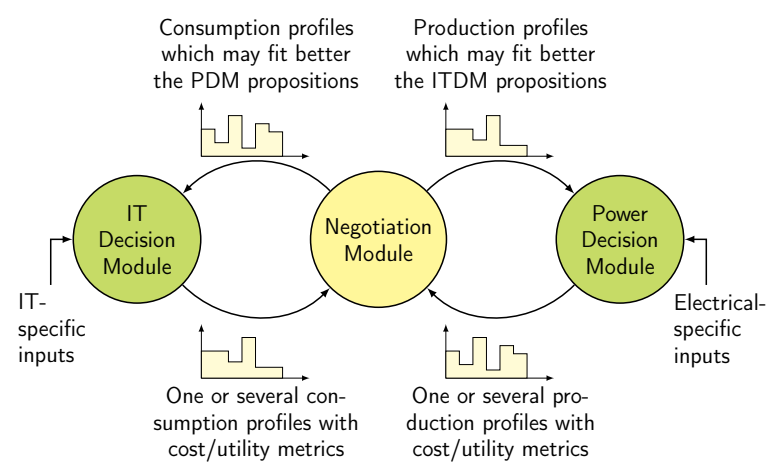

Figure 1 Illustration of the negotiation process, with the information exchanged between the decision modules and the negotiation module.

Then, according to the negotiation phase, we propose several optimization problem consisting of three main objectives: (i) proposing which power profile (constant or not), on a given period of time, the electrical part is able to produce in order to supply the IT part; (ii) proposing alternative power profiles based on a power profile given as an input by the negotiation module and (iii) proposing electrical power commitment in a given time window if we know the expected power demand of the data center that has to be satisfied. Only the power source commitment (iii) is an input of the power system [34]. The other optimization results computed by (i) and (ii) are sent to the negotiation module to help the negotiation process to converge. Once the convergence is obtained, the chosen power profile is delivered to the power decision module to compute the step (iii) as mentioned before. The optimization is based on the optimal solution of the addressed problem by Mixed Integer Linear Programming (MILP) as presented in the following.

This paper is organized as follows: Section 2 is dedicated to related works. In Section 3 we are proposing electrical component models on which constraints of the electrical part are based. Section 4 is focusing on the addressed problem within this paper. Section 5 describes the linearization of the previous non-linear models. Additional constraints and three objective functions are also given in this section to define three MILPs, each of them corresponding to one problem (i), (ii) and (iii) described above. Section 6 shows the usage of the Power Decision Module (PDM) that optimally solves addressed optimization problems. As a result of our approach, traces of executions are given to illustrate the PDM use in a time window of 72 hours. 


\section{Related work}

Taking into account climate change, oil depletion, increasing population and increasing energy demand, energy saving has become a major concern for the world in general and in the computing domain in particular. A large variety of research are working on reducing CO2 emissions and optimizing energy consumption. For instance, Oró et al. and Kaur et al. presented these surveys $[24,33]$ where they summarize all the technologies and tools that can be used in data centers to decrease their energy consumption.

Among many alternative energy sources, using green energy to power data centers can be considered as an attractive solution to succeed in energy saving and reducing gaz emissions. For example, Microsoft's data center in Quincy, WA consumes $48 M W$ of electricity, enough to power 40,000 homes [23]. In Thibodaux, a city in Louisiana state planned a wind power data center project in urban area [39].

Following Greenpeace report [6] of 2017, the consumption of data centers reached $7 \%$ of the world's energy consumption, of which the half was dedicated to cooling [26]. Moreover, the AMD report [29] estimated that the electricity consumption of all data centers in the world costs 7.2 billion per year. Unfortunately, this consumption has a negative impact on the environment as the majority of electricity is produced from fossil resources.

To further reduce the part of fossil fuels, many researchers are interested either in managing the energy resources to meet the user demand (Section 2.1), or in optimizing the use of the computing and the network resources to reduce overall energy consumption (Section 2.2).

\subsection{Managing energy sources in data centers.}

Uddin et al. [40, 41] have proposed papers and surveys that address energy efficiency and CO2 mitigation strategies and techniques in data centers to reduce the effect of global warming. A wide variety of research tackles the use of batteries in data centers [13, 14, 25, $42,44]$. These studies show that the use of the storage can lower both of the capital cost of the power delivery infrastructure and the operating cost of a data center. In addition, in almost all these papers, authors consider a workload with available grid power. Nevertheless, none of these works have taken into consideration the use of renewable energy sources. Then, many papers consider the coordination among multiple power sources in data centers. For instance, Arlit et al [3] have introduced a management architecture that optimizes the combination of power grid usage and renewable energy sources (RES) from an economic point of view by balancing the demand for computing and resource availability with supply side constraints. In [8], Deng et al. have proposed online control policies that uses different characteristics of multiple power sources in order to minimize operation cost. These researchers have used Lyapunov optimization and made a control algorithm which does not depend of statistics of system dynamics. Results show that it provides the trade-off capability between the operational cost, the data center availability, and the uninterruptible power supply lifetime. The algorithm also achieves the robustness to time-varying power demand and supply. Another paper has considered the coordination among multiple power sources in green data centers [28]. In this paper, Li et al. have considered that data centers have base-load power supply, intermittent power supply, and backup energy storage. The authors argue that existing studies typically assume certain specific types of renewable energy sources, and overlook the benefits of cross-source coordination. Then, the authors have proposed a hierarchical power coordination scheme, taking into consideration the timing and capacity of different renewable energy sources. With this scheme, the data centers can make multi-objective power management decisions, based on the available base-load power output, renewable power variability, battery capacity, and IT jobs. Similarly, in [36] the source scheduling is based on a priority scheme in order to maximize the use of renewable energy. Thus the power consumption from the grid is minimized. A dynamic power technique is used to cap the energy used from the grid. In [12], Goiri et al. have developed a prototype of an ecological data center connected to the grid in a small container including a set of solar panels, an electric battery and inverters. In their management algorithm, the authors have taken into consideration the electricity consumption and its cost. The results show that this algorithm can produce integrated workload and energy source schedules for a low electricity costs.

\subsection{Managing workloads in data centers}

Work has also been done to optimize IT resources by two ways. The first concerns the possibility to address the problem of scheduling computation tasks under energetic constraints [22, 27], problems of allocation and resource management with server shutdown, migration of virtual machines, network traffic management $[5,11$, 
$32,37]$. The other direction consists in imagining energy aware IT architectures [16, 21].

An early work on green energy utilization in data centers by Aksanli et al. [1] shows the importance of power prediction. The authors designed an adaptive data center job scheduler capable of reducing the number of aborted jobs and improving the green energy utilization. In [10, 11], the authors propose GreenSlot which is a batch scheduler for parallel tasks. The aim is to reduce the brown power consumption of a data center partially powered by solar panels. In GreenSlot, computation jobs have deadlines and the scheduler first reserves resources for these jobs with lower slack (distance from latest possible start time to current time). Based on weather forecasting and power prediction, GreenSlot schedules the tasks on time slots. However the authors do not try to optimize their schedules. They just reduce the consumption and costs while meeting as much deadlines as possible. Similarly [30] presents a holistic approach to optimize the energy cost with incomes from running a batch of jobs and outcomes to buy brown energy. The paper also provides a proposition for net zero scheduling batch of jobs. It is however based on virtualization and is not bounded by the number of resources.

None of the aforementioned work deals with computing resources provisioned with $100 \%$ renewable energy that we consider in this paper. The ANR DATAZERO project aims at conceiving an innovative structure of a data center. The DATAZERO IT modules are explained in papers $[5,37]$. In the following, the IT load (set of jobs) is converted into a hourly power profile once scheduled. On the other hand, the management of the renewable energy sources of the power decision module $(\mathrm{PDM})$ is explained in the rest of this paper.

\section{Model}

As mentioned before, the power supply system of the data center consists of photovoltaic panels, a wind farm, an energy storage system (ESS) made of a battery bank, regenerative hydrogen energy units composed of proton exchange membrane fuel cell systems (FC) combined with power exchange membrane electrolyzers (EZ) units to supply the data center as shown in Figure 2. This hybrid system works as follows:

- Solar panels (photo-voltaic panels - PV) and wind turbines (WT) constitute the primary sources to supply the data center. In this paper, all PV (resp. WT) are identical. Then, such sources are considered as a unique PV (resp. WT) system.
- Batteries and hydrogen system are the secondary sources, working as storage elements respectively for short term (within a day) and long term storage (seasonal). In this paper, all batteries (resp. fuel cells and electrolyzers (EZ)) are considered as one battery (resp. one FC and EZ).

Moreover, to ensure the sustainability of the data center, the storage level of hydrogen must follow a predefined level LOHtarget $_{D}$ ) for each day $D$ of a year. We assume that this target is known. It can be obtained thanks to a sizing and weather trend studies depending on the location of the data center. This study constitutes a challenging issue that is not addressed in this paper but is included in the ANR DATAZERO project.

In order to properly analyze and implement this hybrid system, it is mandatory to describe the model of each component. For that, Table 1 lists all the notations used in the following sections. First of all, let $\mathcal{H}=K \Delta t$ a time window discretized into $K$ identical periods of duration $\Delta t$ unit of time.

Depending on the case, let $k \in \llbracket 0, K \rrbracket$ be defined as both the $(k+1)$ th time step at instant $k \Delta t$ from the beginning of $\mathcal{H}$ and the index of the $(k+1)$ th period $\Delta t$ of $\mathcal{H}$ defined between the two time step $k$ and $k+1$, i.e., $k=0$ designs the first time step of $\mathcal{H}$ and $k=K$ the first time step of the next time window.

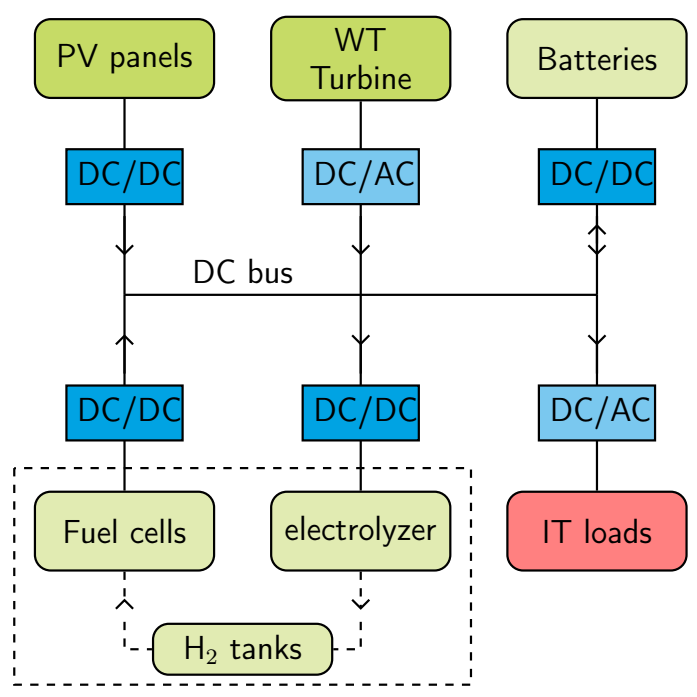

Figure 2 Structure of the DC microgrid supplying the data center loads (source: Robin Roche).

The model of this hybrid renewable energy system is defined as follows:

- Photovoltaic panels: The relation between the irradiation data $I_{k}$ at time step $k$, the area of the PV 
Table 1 Nomenclature

\begin{tabular}{|c|c|}
\hline Notations & Description \\
\hline \multicolumn{2}{|r|}{ Time discretization } \\
\hline $\mathcal{H}$ & \multirow{4}{*}{$\begin{array}{c}\text { a given time window } \\
\text { interval of time between two time steps } \\
\text { index for one time step within } \mathcal{H} \\
\text { number of time steps within } \mathcal{H}\end{array}$} \\
\hline$\Delta t$ & \\
\hline$k$ & \\
\hline$K$ & \\
\hline \multicolumn{2}{|r|}{ Solar panel } \\
\hline$A_{p v}$ & $\mathrm{PV}$ area $\left[\mathrm{m}^{2}\right]$ \\
\hline$\eta_{p v}$ & PV efficiency [\%] \\
\hline$I_{k}$ & \multirow{2}{*}{$\begin{array}{c}\text { Solar irradiation of tilted surface }\left[k W \cdot m^{-2}\right] \\
\mathrm{PV} \text { power }[k W]\end{array}$} \\
\hline$P p v_{k}$ & \\
\hline \multicolumn{2}{|r|}{ Wind turbines } \\
\hline$A_{w t}$ & WT rotor swept area $\left[\mathrm{m}^{2}\right]$ \\
\hline$\eta_{w t}$ & WT efficiency $[\%]$ \\
\hline$P_{r}$ & rated power of the WT $[k W]$ \\
\hline$P w_{k}$ & WT power produced $[k W]$ \\
\hline \multicolumn{2}{|r|}{ Batteries } \\
\hline Cbat & \multirow{9}{*}{$\begin{array}{c}\text { the maximal capacity of the battery }[k W h] \\
\text { State of Charge (SOC) upper limit }[\%] \\
\text { SOC lower limit }[\%] \\
\text { Battery charge efficiency }[\%] \\
\text { Battery discharge efficiency }[\%] \\
\text { Battery self-discharge rate }[\%] \\
\text { SOC at instant } k \Delta t[\%] \\
\text { Power used to recharge battery }[k W] \\
\text { Power discharged from battery }[k W]\end{array}$} \\
\hline$S O C \max$ & \\
\hline SOCmin & \\
\hline$\eta_{c h}$ & \\
\hline$\eta_{d c h}$ & \\
\hline$\sigma$ & \\
\hline$S O C_{k}$ & \\
\hline$P c h_{k}$ & \\
\hline$P d c h_{k}$ & \\
\hline \multicolumn{2}{|r|}{ Electrolyzer } \\
\hline Pezmax & Electrolyzer power upper limit [\%] \\
\hline Pezmin & Electrolyzer power lower limit [\%] \\
\hline$\eta_{e z}$ & Electrolyzer efficiency [\%] \\
\hline $\mathrm{Pez}_{k}$ & Power put into electrolyzer $[k W]$ \\
\hline$Q e z_{k}$ & Electrolyzer $\mathrm{H}_{2}$ mass $[\mathrm{kg}]$ \\
\hline \multicolumn{2}{|r|}{ Fuel Cell } \\
\hline Pfcmax & \multirow{4}{*}{$\begin{array}{c}\text { Maximum power delivered by fuel cell }[k W] \\
\text { Fuel Cell efficiency }[\%] \\
\text { Power delivered by fuel cell at } k \Delta t[k W] \\
\text { Fuel cell } \mathrm{H}_{2} \text { mass }[k g]\end{array}$} \\
\hline$\eta_{f c}$ & \\
\hline$P f c_{k}$ & \\
\hline$Q f c_{k}$ & \\
\hline \multicolumn{2}{|r|}{ Hydrogen tank } \\
\hline LOHtarget $_{D}$ & \multirow{6}{*}{ 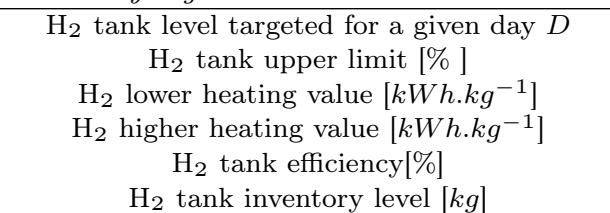 } \\
\hline$L O H \max$ & \\
\hline$L H V h_{2}$ & \\
\hline $\mathrm{HHVh}_{2}$ & \\
\hline$\eta_{\operatorname{tank}}$ & \\
\hline$L O H_{k}$ & \\
\hline & others \\
\hline$\eta_{i n v}$ & Converter efficiency [\%] \\
\hline$x_{k}$ & Battery in use $\left(x_{k}=1\right)$ or not $\left(x_{k}=0\right)$ \\
\hline$y_{k}$ & Electrolyzer in use $\left(y_{k}=1\right)$ or not $\left(y_{k}=0\right)$ \\
\hline$z_{k}$ & $H_{2}$ in charge $\left(z_{k}=1\right)$ or discharge $\left(z_{k}=0\right)$ \\
\hline$u_{k}$ & used in the mutual exclusion ( $H_{2}$ vs batteries) \\
\hline$v_{k}$ & used in the mutual exclusion ( $H_{2}$ vs batteries) \\
\hline
\end{tabular}

panels $A_{p v}$, PV panels efficiency $\eta_{p v}$ and the output power $P p v_{k}$ of the PV panels defined for each period $k(k \in \llbracket 0, K-1 \rrbracket)$, is described as follows for the whole time period $\Delta t$ that begins at instant $k \Delta t$ :

$P p v_{k}=I_{k} \times A_{p v} \times \eta_{p v}$
- Wind turbines: The total power output $P w t_{k}$ defined for each period $k(k \in \llbracket 0, K-1 \rrbracket)$ of the wind turbine generator as a function of the total swept area by the blades $A_{w t}$ and the efficiency of the wind turbine $\eta_{w t}$ is given in the following equation:

$P w t_{k}=P w_{k} \times A_{w t} \times \eta_{w t}$

where $P w_{k}$ follows the mathematical model (3) depending on the wind speed values:

$$
P w_{k}=\left\{\begin{array}{lll}
0 & \text { if } & V_{k} \leq V c i \\
P r \cdot \frac{V_{k}-V c i}{V r-V c i} & \text { if } & V c i<V_{k} \leq V r \\
P r & \text { if } & V r<V_{k} \leq V c o \\
0 & \text { if } & V c o<V_{k}
\end{array}\right.
$$

where $V_{k}$ in the wind speed between time steps $k$ and $k+1, V_{c i}$ is the cut in wind speed for which the wind turbine start working, $V_{c o}$ is the cut out wind speed for which the wind turbine stops working, $V_{r}$ is the rated wind speed for which the wind turbine operate in its rated power $P_{r}$.

- Batteries: The charging and discharging equations of the battery are calculated for each $k$ with $k \in$ $\llbracket 1, K \rrbracket$ respectively in Equations (5) and (6) and with respect to the previous state of charge of the battery $S O C_{k-1}$, the self-discharge rate $\sigma$, the maximal capacity of the battery $C b a t$, the charging, discharging power $P c h_{k-1}, P d c h_{k-1}$ and the charging, discharging efficiency $\eta_{c h}, \eta_{d c h}$. Let $S O C_{0}$ be the initial state of the charge of the battery at the beginning of the current horizon $\mathcal{H}$ in the following equations:

$$
\begin{array}{r}
S O C_{k}=S O C_{k-1} \times(1-\sigma) \\
+\frac{P c h_{k-1} \times \eta_{c h} \times \Delta t-\frac{P d c h_{k-1}}{\eta_{d c h}} \times \Delta t}{C b a t} \\
\text { with } \quad S O C \text { min } \leq S O C_{k} \leq S O C \text { max }
\end{array}
$$

The battery energy system (BES) cannot charge and discharge at the same time. In fact, the charging process ends when either the BES system reaches its maximum capacity or the available energy by renewable sources dedicated to be stored is charged on the BES.

$S O C_{k}=\min \left\{S O C_{k-1} \times(1-\sigma)\right.$ 
$\left.+\frac{P c h_{k-1} \times \eta_{c h} \times \Delta t}{C b a t}, S O C \max \right\} \quad$ if $P c h_{k-1}>0$

$$
\begin{aligned}
& S O C_{k}=\max \left\{S O C_{k-1} \times(1-\sigma)\right. \\
& \left.-\frac{P d c h_{k-1}}{\eta_{d c h} C b a t} \times \Delta t, S O C m i n\right\} \quad \text { if } P d c h_{k-1}>0
\end{aligned}
$$

On the contrary, if the energy production cannot satisfy the energy demand, the battery starts the discharging process either until its lower capacity limit is reached or the load demand is completely met by the energy sources production.

- Electrolyzer: As explained in [4], the output power of the electrolyzer $P e z_{k}$ able to produce the $H_{2}$ mass $Q e z_{k}$ during $\Delta t$ is defined for each period $k(k \in$ $\llbracket 0, K-1 \rrbracket)$ as follows:

$P e z_{k} \times \Delta t=\frac{H H V h_{2} \times Q e z_{k}}{\eta_{e z}}$

with Pezmin, Pezmax the operating range of the electrolyzer such that Pezmin $\leq P e z_{k} \leq$ Pezmax, $Q e z_{k}$ the mass of $H_{2}$ produced by the electrolyzer during $\Delta t$ in $(k g), \eta_{e z}$ the efficiency of the electrolyzer and $H H V h_{2}$ hydrogen higher heating value.

- Fuel Cell: The output power of the fuel cell $P f c_{k}$ is calculated at any time during each period $k(k \in$ $\llbracket 0, K-1 \rrbracket)$ in the following equation:

$P f c_{k} \times \Delta t=L H V h_{2} \times Q f c_{k} \times \eta_{f c}$

with $P f c_{k} \leq P f c m a x, Q f c_{k}$ the $H_{2}$ mass consumed by the fuel cell during $\Delta t, \eta_{f c}$ the efficiency and $L H V h_{2}$ the low heating value of hydrogen.

- Hydrogen tank: The hydrogen produced by the electrolyzer and consumed by the fuel cell is stored in tanks. Thus, the level of hydrogen in the tank is calculated at any time during each period $k$ with $k \in \llbracket 1, K \rrbracket$ as follows:

$$
\begin{gathered}
L O H_{k}=L O H_{k-1}+Q e z_{k-1}-Q f c_{k-1} / \eta_{\text {tank }} \\
\text { with } 0 \leq L O H_{k} \leq L O H \max
\end{gathered}
$$

Let $L O H_{0}$ be the initial value of the level of hydrogen.

Considering the previous simplified model for all energy sources, we propose to show how they can be used to solve the optimization problems we face.

\section{Problem statement}

The negotiation module aims to guide both the decision optimization modules (ITDM and PDM) in order to converge to a power profile, first, close to the one requested by IT and second, feasible by the electrical part. In evidence, the IT decision module would prefer to execute jobs when that is better for Quality of Service (QoS) constraints. However, it most likely may not match with the best usage of renewable energy and storage devices. Then, it is mandatory to confront IT requests with the energy availability which is computed by the PDM. As a consequence, the strategy describing the exchange of power profiles between the three modules is done as illustrated in Figure 3 and is explained in details in the next subsection.

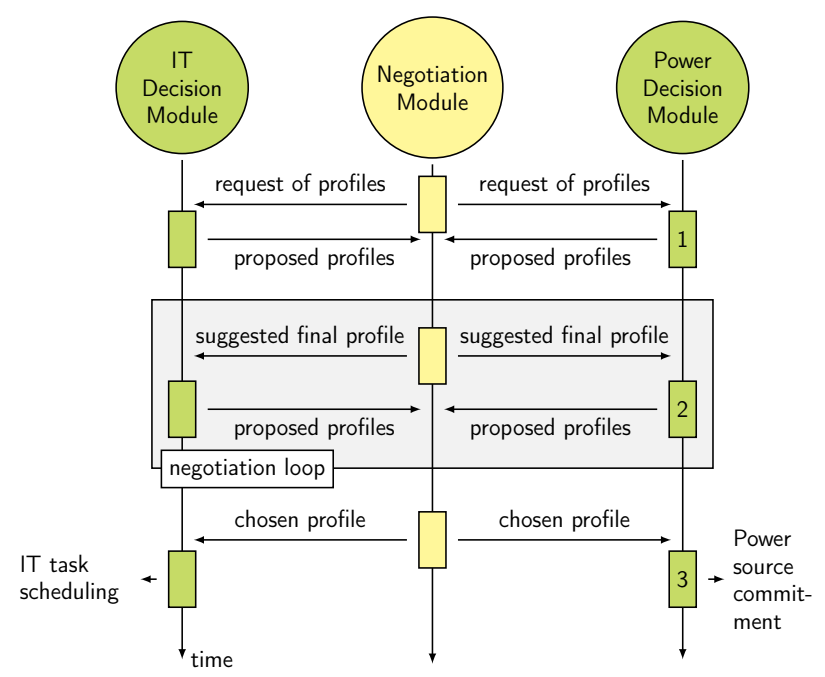

Figure 3 Illustration of the negotiation process, with the information exchanged between the both decision modules (ITDM and PDM) and the negotiation module.

Thus, the negotiation module forces both ITDM and PDM to design one or multiple power profiles and to send them for each negotiation round. In order to converge and to find the best source commitment for both modules, each power profile sent must be different from the one sent in the previous negotiation round. Therefore, the power decision module addresses different optimization problems according to the purpose of the work and the constraints of the system. The primary goal of the power management system consists in defining the best commitment to satisfy the power demand. To make the optimization process readable, the list of notations used is summarized in Table 1. 


\subsection{Strategies of the power decision module}

As seen previously in the negotiation process, several kind of requests are asked to the power management module. This leads to design different kind of power profiles depending on the round of negotiation. So, we can define several optimization programs, each specifically addressing one of the underlying problems. In the strategy proposed (see Figure 3), the negotiation module (NM) starts by requesting different power profiles. PDM has to identify which source commitment can be proposed regarding the energy storage levels and the weather forecasting (green box labeled 1 in Figure 3). This is done following two different goals:

- Providing the maximum constant power profile that the infrastructure is able to produce while respecting all the constraints and the storage state and taking the weather forecasting during the current horizon into account. This process is detailed in Section 6.1.

- Providing a non constant power profile that optimize the power production without using the storage devices. As using the storage devices involves losses because of their efficiency, the power profile given would be the one produced by the renewable sources. This process is detailed in Section 6.2.

In the second round of the negotiation, the NM sends a power profile and asks to design a new profile that is close to the given one (green box labeled 2 in Figure 3 ). In this case, the optimization program has another goal:

- Matching with the given load profile: the problem consists in finding an alternative power profile as close as possible to the profile required by the NM. If this profile is not reachable, the power constraint is relaxed using a given rate (relaxation factor). Additional constraints and variables force the power production for each period to be over the values of the relaxed power profile while respecting the constraints defined by the model and the storage state. This process is detailed in Section 6.3.

Once the negotiation ends, the NM send the chosen profile to both PDM and ITDM. Then, PDM has to find the best commitment of the power sources to answer to that chosen profile (green box labeled 3 in Figure 3). This third problem follows another goal:

- Satisfying the load demand. The strategy proposed is to maximize the long-term storage (i.e. the hydrogen storage) by setting a target level of stored hydrogen to reach at the end of the horizon. This allows ensuring the seasonality variation of renewable energy production. This process is detailed in Section 6.4.

From another part, the PDM represents the order for the Power source manager which is responsible for the electrical power command that the latter has to respect. In fact, the electrical sources must follow the commitment of the PDM. All the previously described strategies are based on common constraints that translate the physical laws of the power system. The remainder of this section describes those constraints.

\subsection{Flow conservation}

The power produced $\left(P w t_{k}+P p v_{k}\right)$ by the primary sources during the whole period $k$ is used for three purposes:

- Hydrogen production $\left(P e z_{k}\right)$,

- Charging the batteries $\left(P c h_{k}\right)$,

- Satisfaction of the data center demand $\left(\operatorname{Pload}_{k}\right)$.

In case there is not enough renewable energy to meet the demand $\left(\right.$ Pload $\left._{k}\right)$, additional electrical power is delivered by the fuel cells $\left(P f c_{k}\right)$ and batteries $\left(P d c h_{k}\right)$. To satisfy the demand, the following equation should be fulfilled for each $k$ with $k \in \llbracket 0, K-1 \rrbracket$ :

$$
\begin{aligned}
\operatorname{Pload}_{k} & \leq P w t_{k}+P p v_{k} \\
& +\left(P f c_{k}+P d c h_{k}-P e z_{k}-P c h_{k}\right) \times \eta_{i n v}
\end{aligned}
$$

\subsection{Constraint Satisfaction Problem}

The resulting model can be viewed as a Constraint Satisfaction Problem (CSP). This model is linearized in the next section to be solved using an efficient solver as Gurobi [15]. This allows proposing solutions optimally computed by the PDM: (i) identification of the profile that maximizes the power produced, (ii) computation of an optimal commitment around a target profile considering a given relaxation factor, and (iii) computation of an optimal commitment constrained by the load profile.

As a result, the CSP is defined as follows (with $k \in$ $\llbracket 0, K-1 \rrbracket$ or $k \in \llbracket 0, K \rrbracket$ for $S O C_{k}$ and $L O H_{k}$ variables): 


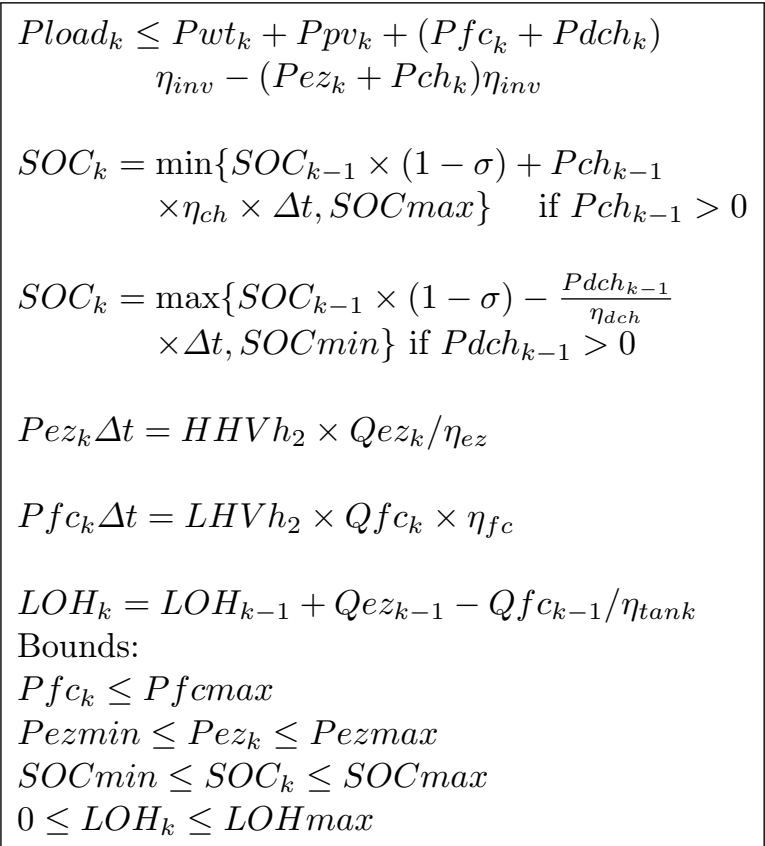

\subsection{Context of the resolution}

In addition, common sense rules have to be considered to allow the use of power components without any time restriction if the two following constraints are respected:

- When fuel cells start working, it is only used to satisfy the demand and not to charge batteries.

- When batteries start discharging, they are only used to satisfy the demand and not to produce hydrogen.

In the next section, we propose to transform the CSP in a linear constraint satisfaction problem.

\section{Constraint Linearization}

In this section, in order to be solved, the proposed CSP (11) is linearized.

\subsection{Linearization of the constraints}

Each non linear constraint of the model is transformed to obtain a linear constraint.

\subsubsection{The battery state of charge}

The state of charge of the battery is limited by the SOC range (SOCmin and SOCmax) with $k \in \llbracket 0, K \rrbracket$ and depends both on the charge and discharge phases:

$$
\left\{\begin{array}{l}
S O C \min \leq S O C_{k} \leq S O C \max \\
S O C_{k}=S O C_{k-1}(1-\sigma) \\
\quad+\frac{P c h_{k-1} \Delta t \times \eta_{c h}-P d c h_{k-1} \Delta t / \eta_{d c h}}{C b a t}
\end{array}\right.
$$

As the battery can not charge and discharge at the same time, we introduce the set of binary variables $x_{k}$, and two sets of variables $P c h_{k}^{\prime}, P d c h_{k}^{\prime}$ with $k \in \llbracket 0, K-1 \rrbracket$ such as:

$\left\{\begin{array}{l}P c h_{k}=x_{k} \times P c h_{k}^{\prime} \\ P d c h_{k}=\left(1-x_{k}\right) \times P d c h_{k}^{\prime}\end{array}\right.$

where $x_{k}=0$ means that the battery is discharging and $x_{k}=1$ means that the battery is charging. In this way, the battery can not charge and discharge at the same time. Then we propose to rewrite the previous state of charge equations as the following:

$$
\left\{\begin{array}{l}
S O C \min \leq S O C_{k} \leq S O C \max \\
S O C_{k}=S O C_{k-1}(1-\sigma) \\
\quad+\frac{x_{k} \times P c h_{k-1}^{\prime} \times \Delta t \times \eta_{c h}-\left(1-x_{k}\right) \times P d c h_{k-1}^{\prime} \Delta t / \eta_{d c h}}{C b a t}
\end{array}\right.
$$

Due to these substitutions, we add new constraints to linearize Equation (14):

$$
\left\{\begin{array}{l}
0 \leq P c h_{k} \leq P c h \max \\
P_{c h} \geq 0 \\
P c h_{k} \leq x_{k} \times P c h m a x \\
P c h_{k} \leq P c h_{k}^{\prime} \\
P c h_{k} \geq P c h_{k}^{\prime}-\left(1-x_{k}\right) P c h \max
\end{array}\right.
$$

$$
\left\{\begin{array}{l}
0 \leq P d c h_{k} \leq P d c h \max \\
P d c h_{k} \geq 0 \\
P d c h_{k} \leq\left(1-x_{k}\right) \times P d c h \max \\
P d c h_{k} \leq P d c h_{k}^{\prime} \\
P d c h_{k} \geq P d c h_{k}^{\prime}-x_{k} P d c h \max
\end{array}\right.
$$

Because Equation (13) is not written within the final linear program, the fact that the battery can not 
charge and discharge is introduced by other new equations:

$$
\left\{\begin{array}{l}
P c h_{k} \leq x_{k} \times P \operatorname{chmax} \quad \text { with } \quad k \in \llbracket 0, K-1 \rrbracket \\
P d c h_{k} \leq\left(1-x_{k}\right) \times P d c h m a x \quad \text { with } \quad k \in \llbracket 0, K-1 \rrbracket \\
x_{k} \in\{0,1\}
\end{array}\right.
$$

where Pchmax and Pdchmax are the respective upperbound of $P c h_{k}$ and $P d c h_{k}$.

Battery operation: The battery is supposed to balance underproduction and overproduction during a period of time $T$. For instance if $T=24 h$ with $\Delta t=1 h$ and $K=$ 24 , batteries are used for the fluctuations between day and night. It means that the production is smoothed over the day. To make it possible, the level of the state of charge of the battery $S O C_{K}$ should be its value at the beginning $S O C_{0}$ of each period $T$. This operation is explained by the following to fix values before the resolution of the program if $T$ is larger than $24 h$ (one day):

$$
\left\{\begin{aligned}
S O C_{K}= & S O C_{0}=\text { SOCinit if } K<T=24 \\
S O C_{k}= & S O C_{0}=\text { SOCinit if } K \geq T=24 \\
& \text { and } k \% 24=0(k \in \llbracket 0, K \rrbracket)
\end{aligned}\right.
$$

with SOCinit the right level of charge to make possible the daily power compensation from hours where an extra renewable production is existing to hours this production is lacking. That is why this level has to come back to the same level each day. The difference between days is compensated by using long term storage.

\subsubsection{Electrolyzer}

As explained in Section 3 (Model), the electrolyzer operates only while respecting the power range, otherwise it does not work and its power equals zero. The following bounds express these cases:

$$
\begin{cases}\forall k \in \llbracket 0, K-1 \rrbracket & \text { Pezmin } \leq \text { Pe } z_{k} \leq \text { Pezmax } \\ \forall k \in \llbracket 0, K-1 \rrbracket & \text { Pez } z_{k} \geq 0\end{cases}
$$

It is then necessary to introduce a set of binary variables $y_{k}$ (with $\left.k \in \llbracket 0, K-1 \rrbracket\right)$ to model the two alternatives where: $-y_{k}=1$ means that the electrolyzer is in use with Pezmin $\leq$ Pe $z_{k} \leq$ Pezmax during period $k$,

$-y_{k}=0$ means that the electrolyzer is stopped during period $k$.

By adding this binary variables, Equations (19) become:

$\left\{\begin{array}{l}\left(1-y_{k}\right) \times \text { Pez } z_{k}=0 \\ y_{k} \times \text { Pe } z_{k} \leq \text { Pezmax } \\ y_{k} \times \text { Pez } z_{k} \geq y_{k} \times \text { Pezmin } \\ y_{k} \in\{0,1\}\end{array}\right.$

Due to the non linearity of the set of Constraints (20), we propose to add a new substitution of variable $P e z_{k}^{\prime}$ to keep $P e z_{k}$ being the relevant variables that express the use of the electrolyzer. We define the following relation to make the linearization possible:

$P e z_{k}=y_{k} \times P e z_{k}^{\prime}$

then we add the following equations to linearize (20):

$\left\{\begin{array}{l}P e z_{k} \leq P e z_{k}^{\prime} \\ P e z_{k} \geq 0 \\ P e z_{k} \leq y_{k} \times \text { Pezmax } \\ P e z_{k} \geq P e z_{k}^{\prime}-\left(1-y_{k}\right) \text { Pezmax } \\ 0 \leq P e z_{k}^{\prime} \leq \text { Pezmax } \\ \text { Pe } z_{k} \geq y_{k} \times \text { Pezmin } \\ y_{k} \in\{0,1\}\end{array}\right.$

\subsubsection{Hydrogen tank level}

As mentioned before for the battery, it is necessary to manage $Q f c_{k}$ and $Q e z_{k}$ in order to control the hydrogen mass flow circulating in the hydrogen tank as mentioned in Equation (9). Equations (7), (8) and (9) can be written by considering the new definition of $Q e z_{k}$ and $Q f c_{k}$ for $k \in \llbracket 0, K \rrbracket$ :

$$
\left\{\begin{array}{l}
P e z_{k} \Delta t=H H V h_{2} \times Q e z_{k} / \eta_{e z} \\
P f c_{k} \Delta t=L H V h_{2} \times Q f c_{k} \times \eta_{f c} \\
L O H_{k}=L O H_{k-1}+Q e z_{k-1}-Q f c_{k-1} / \eta_{\text {tank }}
\end{array}\right.
$$


Therefore, additionally to the two new sets of variables $Q e z_{k}^{\prime}$ and $Q f c_{k}^{\prime}$, we introduce an other set of binary variables $z_{k}$ to model the two alternatives where the fuel cells are in use or not (with $k \in \llbracket 0, K-1 \rrbracket)$. As before and for the same reasons, let be the following variable substitutions:

$$
\left\{\begin{array}{l}
Q e z_{k}=z_{k} \times Q e z_{k}^{\prime} \\
Q f c_{k}=\left(1-z_{k}\right) \times Q f c_{k}^{\prime}
\end{array}\right.
$$

where:

$-z_{k}=1$ means that $Q f c_{k}=0$

$-z_{k}=0$ means that $Q e z_{k}=0$

then we add the following set of equations:

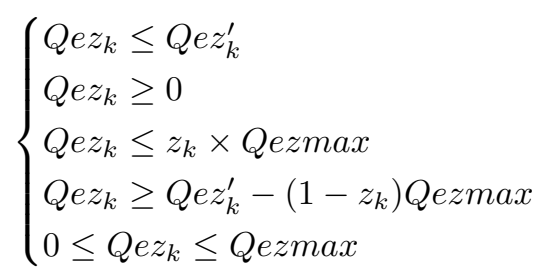

$$
\left\{\begin{array}{l}
Q f c_{k} \leq Q f c_{k}^{\prime} \\
Q f c_{k} \geq 0 \\
Q f c_{k} \leq\left(1-z_{k}\right) \times Q f c \max \\
Q f c_{k} \geq Q f c_{k}^{\prime}-z_{k} \times Q f c \max \\
0 \leq Q f c_{k} \leq Q f c \max
\end{array}\right.
$$

In the rest of the paper, we use these constraints as a basic model for the different usage of the PDM.

\subsection{Additional linear constraints}

As indicated in Section 4.4, let us recall the common sense usage rules.

\subsubsection{Mutual exclusion between hydrogen and battery}

The valid usage cases are:

1. The battery is in charge $\left(x_{k}=1\right)$ while electrolyzer can be in use $\left(y_{k}=0\right.$ or 1$)$ and obviously the fuel cell is stopped $\left(z_{k}=1\right)$.

2. The battery is discharging $\left(x_{k}=0\right)$ then the fuel cell can be in use $\left(z_{k}=0\right.$ or 1$)$ and the electrolyzer has to be stopped $\left(y_{k}=0\right)$.
3. Start and stop of the fuel cell and the electrolyzer are allowed in this problem.

Considering theses rules, there are only 4 available configurations for the variables $x_{k}, y_{k}$ and $z_{k}$ which are listed in Table 2. Constraint (27) represents the solution to these requirements. Conversely the fourth other combinations do not satisfy these constraints.

\begin{tabular}{c|c|c}
$x_{k}$ & $y_{k}$ & $z_{k}$ \\
\hline 0 & 0 & 0 \\
0 & 0 & 1 \\
1 & 0 & 1 \\
1 & 1 & 1 \\
\hline
\end{tabular}

Table 2 Valid configurations for variables $x_{k}, y_{k}$ and $z_{k}$

$$
\left(1-x_{k}\right)\left(1-y_{k}\right)+x_{k} \times z_{k} \geq 1
$$

Due to the non linearity of Constraints (27), we add a new set of variables $u_{k}$ and $v_{k}$ (with $\left.k \in \llbracket 0, K-1 \rrbracket\right)$ that express the mutual exclusion between hydrogen system and battery where:

$$
\begin{aligned}
& -u_{k}=x_{k} \times y_{k} \\
& -v_{k}=x_{k} \times z_{k}
\end{aligned}
$$

then we add the following equation:

$u_{k}+v_{k}-x_{k}-y_{k} \geq 0$

with

$\left\{\begin{array}{l}u_{k} \leq x_{k} \\ u_{k} \leq y_{k} \\ 1-x_{k}-y_{k}+u_{k} \geq 0 \\ u_{k} \geq 0\end{array}\right.$

$\left\{\begin{array}{l}v_{k} \leq x_{k} \\ v_{k} \leq z_{k} \\ 1-x_{k}-z_{k}+v_{k} \geq 0 \\ v_{k} \geq 0\end{array}\right.$

The obtained linear constraint satisfaction problem is used in the following section as a basic model for defining the different mixed integer linear programs designed for solving optimization problems associated with the power decision module. 


\section{Power Decision Module PDM}

The power decision module (PDM) consists in a black box composed by several internal components to ensure the management of the hybrid renewable energy sources by solving different optimization problems corresponding to negotiation rounds. These problems are expressed using linear programming formulation. Thus, as detailed in Section 4.1, the PDM is able to design different profiles depending on the goal it has to ensure.

The problem takes as input the renewable power produced under weather conditions Prenew Pr $=P$ P $v_{k}+$ $P w t_{k}$, power demand Pload $k$ and other information of sizing like the number of wind turbines, the surface area of PV, the energy storage capacity and the efficiency of any component. As a solution, its resolution gives a schedule of each time slot for supply-side source and energy storage usage, according to the availability of renewable power as explained in Section 3.

The optimization problems explained in the next paragraphs are implemented using python and are solved using the GUROBI solver [15]. The power supply sizing and weather conditions are the same for each of the following optimization problems for illustration purpose.

\subsection{Providing a constant power profile Pprod}

In this section, the aim is to obtain a maximum power production Pprod from the primary sources for the whole horizon $\mathcal{H}$, taking into account the efficiency of each storage part used. Then the PDM takes as input the meteorological data (to determine the primary production), the initial values of the storage levels $\left(S O C_{0}\right.$ and $\mathrm{LOH}_{0}$ ) and the target set. As an output, the PDM must send the maximum constant profile and the storage variation $\left(S O C_{k}\right.$ and $\left.L O H_{k}\right)$ to the negotiation module.

To make this possible, some modifications are set in the mixed integer linear program and a new objective function and new constraints are added. To simplify it, the new variables added are explained in Table 3.

Table 3 Additional notations

\begin{tabular}{l|l} 
Notations & Description \\
\hline Porod $_{\text {OHarget }}$ & $\begin{array}{l}\text { The constant power profile }[\mathrm{kW}] \\
\text { A level of hydrogen defined by } \\
\text { the sizing needed to be reached } \\
\text { at the end of the horizon } \mathcal{H}[\mathrm{kg}]\end{array}$
\end{tabular}

\subsubsection{Objective function}

The objective function consists of maximizing the constant power profile obtained from the source commitment Pprod in order to propose a profile in the first part to the negotiation. The problem is thus mathematically translated to:

maximize Pprod

\subsubsection{Additional constraints}

Some constraints are added or modified in order to consider common sense usage rules: consequently, Equation (10) is modified in this program as (32). Another constraint (33) is added to ensure the hydrogen level at the end of the period of simulation reached the target defined. This allows the storage system to handle the next periods.

$$
\begin{aligned}
& \forall k \in \llbracket 0, K-1 \rrbracket \\
& \qquad \text { Pprod } \leq \\
& \qquad \text { Pwt } t_{k}+P p v_{k}+ \\
& \left(P f c_{k}+P d c h_{k}-P e z_{k}-P c h_{k}\right) \eta_{i n v}
\end{aligned}
$$

LOHtarget $_{D} \leq \mathrm{LOH}_{K}$

The hydrogen target level LOHtarget $_{D}$ is supposed to be computed based on long term weather forecasting and IT load consumption for one year. $D$ represents the day number within the current year and matches with the time horizon $K \times \Delta t$. We assume that the

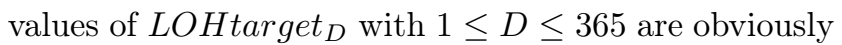
given by the preliminary sizing study of the green data center.

\subsubsection{Obtained model}

The constraints explained in Section 5.1 are used for each version of the PDM as the basic constraints. Then, the linear program able to produce a constant maximum profile using the storage system composed of batteries and hydrogen system is then written as mentioned in the appendix A. 


\subsection{Providing a variable power profile}

In this section, the aim of providing a non constant profile comes from the fact that the data center can start and stops servers depending on its job scheduler. It consist in obtaining a maximum variable power production profile $\operatorname{Pprod}_{k}(k \in \llbracket 0, K-1 \rrbracket)$ from the primary sources, taking into account the efficiency of each storage part used in order to provide multiple profiles to the negotiation module. Then the PDM takes the meteorological data as an input to determine the primary production along the horizon $\mathcal{H}$, the initial values of the storage level $\left(S O C_{0}\right.$ and $\left.L_{0} H_{0}\right)$.

As an output, the PDM must send the maximum power profile, and the storage variation $\left(S O C_{k}\right.$ and $\left.L O H_{k}\right)$ to the negotiation module.

To make this possible, some modifications are set to the linear program obtained in the previous section. To simplify it, the variable Pprod is no longer a constant value during the horizon $\mathcal{H}$ but is changes following each step $k$ in the horizon.

\subsubsection{Objective function}

For this strategy, the objective function consists of maximizing the power profile obtained from the source commitment Pprod in order to address to the data center load. The problem is thus mathematically translated to:

maximize $\sum_{k=0}^{K-1}$ Pprod $_{k}$

\subsubsection{Added constraints}

As in the constant power case, some constraints are added or modified to consider common sense usage rules then Equation (10) is modified in this program as (35) $(\forall k \in \llbracket 0, K-1 \rrbracket):$

$$
\begin{aligned}
\operatorname{Prod}_{k} \leq & P w t_{k}+P p v_{k}+ \\
& \left(P f c_{k}+P d c h_{k}-P e z_{k}-P c h_{k}\right) \eta_{i n v}
\end{aligned}
$$

The same constraint (33) is added to ensure the target level of hydrogen is reached at the end of the period of simulation, so that the storage system is able to handle the next periods.

\subsubsection{Obtained model}

The linear program is able to produce a maximum non constant profile using the storage system composed of batteries and hydrogen system. It is then written as in the appendix B.

\subsection{Matching with a requested profile}

In this subsection, the aim is to obtain a profile which is matching with a profile requested by the negotiation module to end up with the negotiation between both modules. Thus, the PDM takes as an input the data of the profile requested by the negotiation module, the meteorological data to determine the primary production along the horizon $\mathcal{H}$, the initial values of the storage level $\left(S O C_{0}\right.$ and $\left.L O H_{0}\right)$, etc. As an output, the PDM must send the closest profile (Pprod) to the one received by the negotiation module (Pload). To make this possible, some modifications are set for the basic linear program proposed and a new objective function and new constraints are added.

\subsubsection{Objective function}

In order to be able to fulfill the data center demand in every situation (overproduction or underproduction), we add a relaxation factor $\alpha$ capable to relax the power demand in order to create a profile Pprod $_{k}$ that matches the most with the load Pload $_{k}$

Thus the objective function consists in minimizing the value of the relaxation factor $\alpha$ to be as close as possible to the demand.

minimize $\quad \alpha$

\subsubsection{Added constraints}

As in the two previous cases, considering common sense usage rules turns Equation (10) into Equation (35). Constraint (33) is added also in order to force the hydrogen level at the end of the period of simulation $\left(\mathrm{LOH}_{k}\right)$ to be bigger than or equal to the level of hydrogen target. Thus, the storage system is able to handle the next future power requirement. In this stage of the negotiation, in order to satisfy the profile requested by NM, a new constraint is added to the linear program as defined in Equation (37). Therefore, we introduce a $\alpha$ computed by binary research to enable the power produced $\operatorname{Pprod}_{k}$ in each time step $k$ to be greater than or equal to $(1-\alpha) \times$ Pload $_{k}$. 
$\operatorname{Pprod}_{k} \geq(1-\alpha) \times \operatorname{Pload}_{k}$

The feasibility of the linear program depends on the $\alpha$ value:

- if $\alpha=0$ it means that the profile generated is the same as the one provided by the NM;

- if $\alpha=1$ it means that the profile could be entirely different from the one provided.

As the data center load is relaxed, another management is proposed. The solution is thus sub-optimal compared to the initial power demand, but an alternative feasible solution is proposed to overcome the intermittent nature of renewable sources.

\subsubsection{Obtained model}

The linear program able to produce a profile that matches with a given one from the negotiation module using the storage system is then written as mentioned in the appendix C.

\subsection{Source commitment}

This problem is, in fact, the last step of the negotiation process. It is addressed once the negotiation has converged to the appropriate power profile agreed on. This power profile is then sent by the negotiation module to the PDM where used as an input (Pload). Moreover, the PDM takes as input the meteorological data to determine the primary production along the horizon $\mathcal{H}$, the initial values of the storage level $\left(S O C_{0}\right.$ and $\left.L O H_{0}\right)$, etc. As an output, the PDM must give the best usage of the power sources and energy storage for the next period of the next time window $\mathcal{H}$.

\subsubsection{Objective function}

The objective function is to maximize long-term stocks by setting a target level hydrogen to reach at each end of horizon. Target stocks are set by the previsions of renewable energy production and by the capabilities of the components. The problem is thus mathematically translated by supplying the power demand (Constraint (39)) and by maximizing the level of hydrogen $\mathrm{LOH}_{K}$ at the end of the horizon. This objective allows to store the waste of energy available during that time horizon so as to supply underproduction days in the future.

The objective function is defined as:

maximize $L O H_{K}$

\subsubsection{Added constraints}

To satisfy the power demand Pload $_{k}$, the following constraint is added:

$\operatorname{Pload}_{k} \leq \operatorname{Pprod}_{k}$

\subsubsection{Obtained model}

The linear program obtained for the source commitment is defined, $\forall k \in \llbracket 0, K-1 \rrbracket$ for all constraints except $k \in \llbracket 0, K \rrbracket$ for constraints containing variables $S O C_{k}, L O H_{k}, Q e z_{k}, Q f c_{k}, Q e z_{k}^{\prime}$ and $Q f c_{k}^{\prime}$ as mentioned in the appendix D.

\section{Experiments and results}

In this section, the linear programs obtained below are used with the following inputs in order to obtain different optimal commitment of the sources according to the stage of the negotiation. In fact, the program was executed following different resolution time windows for the same horizon (1 year) in [20]. The same sizing is played from the year 2004 till 2012. For each year, several resolution time windows (one week, three days, one day) are simulated with the weather condition of the same year. Simulation results shows that the best resolution time windows is 3 days and that the resolution time is $44.8 \mathrm{~s}$. Experiments are performed on an Intel@ Core $^{T M}$ i5-6200U CPU @ $2.30 \mathrm{GHz} \times 4,8 \mathrm{~GB}$ RAM, 64-bit using Ubuntu 16.04 LTS as exploitation system. The time for solving each simulation is less than 1 minute using Gurobi optimizer [15].

\subsection{Input data}

Weather conditions: To simulate the primary sources production (photovoltaic panels and wind turbines), one needs to download meteorological data such as the solar radiation and wind speed data. These data can be obtained from various database online. In our case, the solar radiation data are downloaded from the National Solar Radiation Database (NSRDB) [35], and the wind speed data are downloaded from the wind prospector from the national Renewable Energy Laboratory (NREL) [9]. These data can be taken every hour during a day starting from 2004 till 2012. The chosen localization is Los Angeles with the following coordinates: Latitude: 34.57; Longitude -118.02; and elevation 807. 
Workload: The workload $\mathcal{W}$ is generated following the data from user requests recorded during the Soccer World Cup in 1998 and available on the web site $^{1}$. We have used the same methodology as in [43]. Each job should not be delayed more than three hours to be complete.

\subsection{Settings}

The input values of the sources used in the power decision module algorithms are summarized in Table 4.

Table 4 Input values of the power supply sizing process

\begin{tabular}{|c|c|c|}
\hline Notation & Value & Units \\
\hline$P_{r}$ & 400 & {$[W]$} \\
$V_{r}$ & 10 & {$[\mathrm{~m} / \mathrm{s}]$} \\
$V_{c i}$ & 4 & {$[\mathrm{~m} / \mathrm{s}]$} \\
$V_{c o}$ & 30 & {$[\mathrm{~m} / \mathrm{s}]$} \\
$\eta_{p v}$ & 0.163 & - \\
$A_{p v}$ & 3149 & $\mathrm{~m}^{2}$ \\
$\eta_{f c}$ & 0.4 & - \\
Pfcmax & 1115 & {$[W]$} \\
$\eta_{e z}$ & 0.4 & - \\
Pezmax & 832.65 & {$[W]$} \\
Pezmin & 50 & {$[W]$} \\
LOHmax & 10000 & {$[\mathrm{~kg}]$} \\
$\eta_{\text {ch }}$ & 0.82 & - \\
Pchmax & 800 & {$[W]$} \\
$\eta_{\text {dch }}$ & 0.82 & - \\
Pchmin & 800 & {$[W]$} \\
Cbat & 1000 & {$[W h]$} \\
\hline
\end{tabular}

In this article, simulations are given on three days (72 hours) for a better illustrations of the results. The chosen 3 days of reference starts from April the 30th to May the 2nd 2004. Considering the sun and the wind, Figure 4 illustrates the power production obtained the respective models of both primary sources. In order to define the renewable energy produced in each hour for a better use of the storage sources, we compute the sum (renewablePower) of each power production for each hour during these three days.

Based on Figure 4, one can notice a complementary between the sun and the wind in electrical power production which justifies the hybridization of the primary sources [18]. For example, at the 20th hour, the solar production is zero caused by the night and day alternation. Nevertheless, the wind turbine reaches its rated output power equals to $400 \mathrm{~kW}$.

\footnotetext{
1 WorldCup'98 logs. http://ita.ee.lbl.gov/html/contrib/ WorldCup.html
}

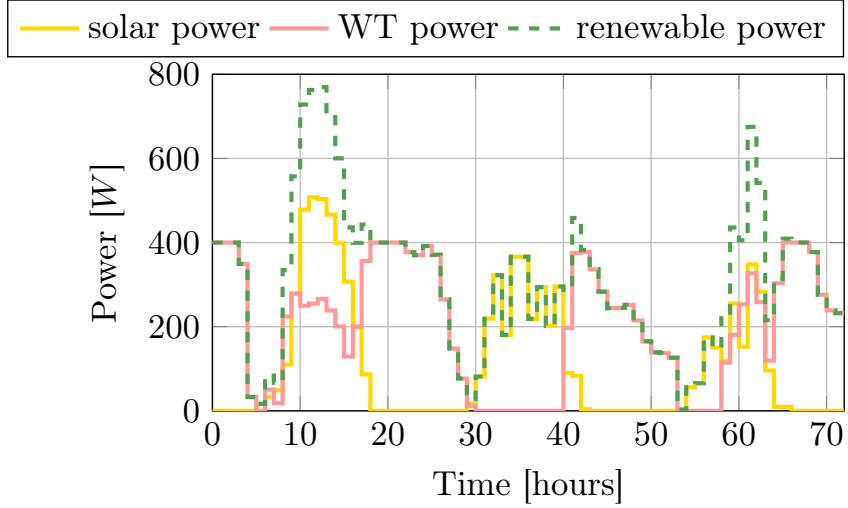

Figure 4 Renewable power production from April the 30th to May the 2nd 2004.

\subsection{Experiment scenarios}

\subsubsection{Results Maximum constant power profile}

In this linear program, we suppose that we are in the first stage of the negotiation which explains the absence of load in Figure 5. Actually, in that step of the negotiation, the PDM is supposed to provide the negotiation with profiles without getting data about the load. The same power architecture as in the previous section is used.

Results presented in Figure 5 are obtained by applying this linear program. The solution gives here a maximum constant power that can be delivered equal to $163 \mathrm{~kW}$. As can be seen in this figure, the battery is responsible of the daily smoothing (day/night alternation). Thanks to Constraint (33), the level of hydrogen is even more than target at the end of the horizon $\mathcal{H}$ $\left(\right.$ LOHtarget $\left._{D}=400 \mathrm{~kg}\right)$ to be able to assist the next horizon.

\subsubsection{Results Maximum Power profile variable}

Results presented in Figure 6 are obtained by applying this linear program. The production power $\operatorname{Pprod}_{k}$ is variable in some time step $k$. The same power architecture is used as in the previous subsections.

Moreover, one can notice that the state of the battery is constant all over the horizon considered. Indeed the system does not use the battery in order to get the best profile Pprod $_{k}$. As the battery cycling efficiency is less than 1, the charging and discharging of the battery would lead to power loss. The level of hydrogen is increasing from $300 \mathrm{~kg}$ to $400 \mathrm{~kg}$ in order to reach the target level. So, Constraint (33) is respected. As many optimal solutions exist, the MILP gives one optimal proposition. For instance, another solution consists in 

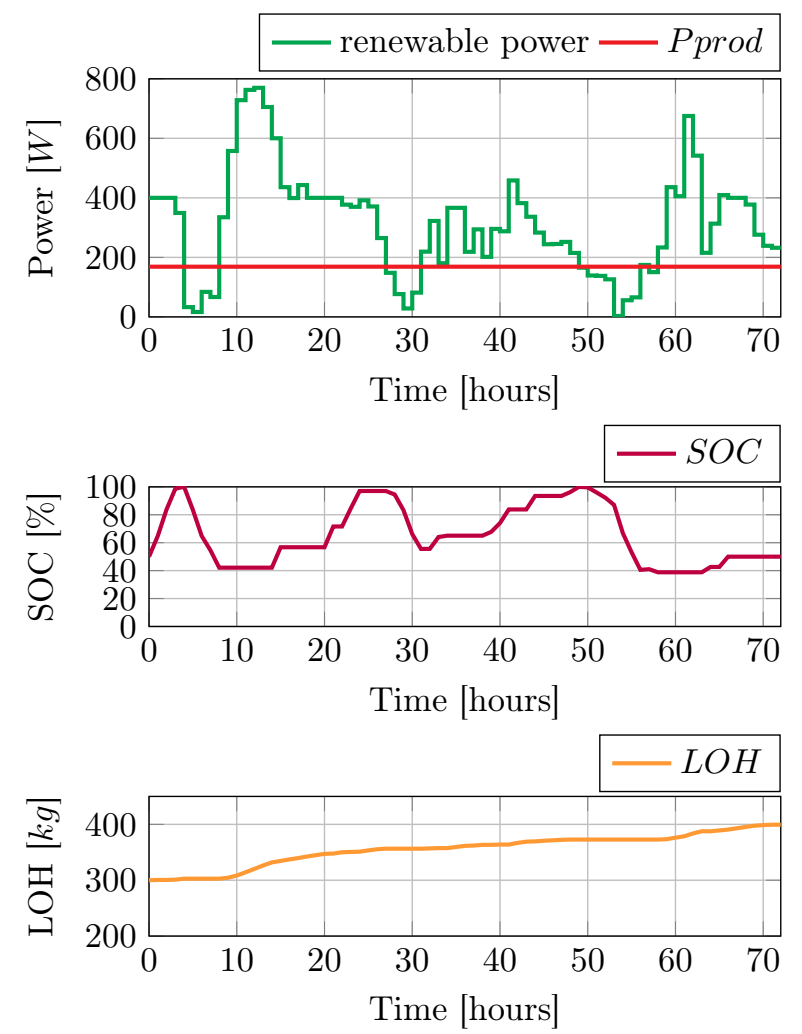

Figure 5 Constant Power Profile management.
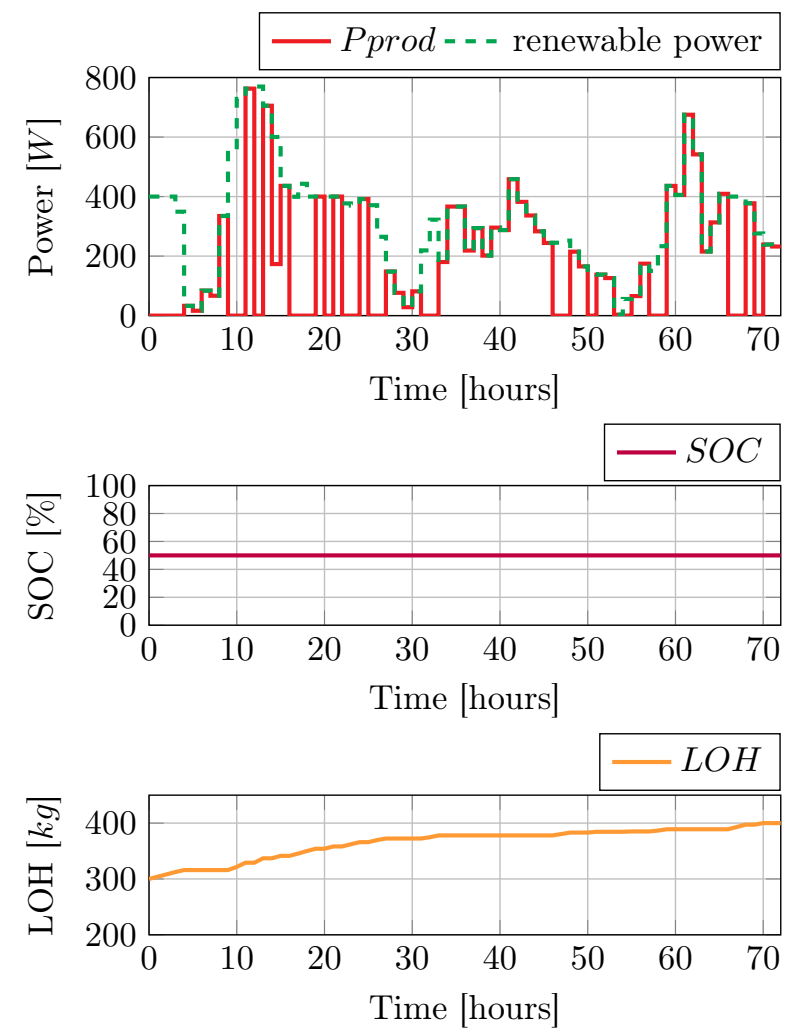

Figure 6 Maximum Power Profile management. charging the $\mathrm{LOH}$ at the beginning of the time horizon and stays constant for period left.

\subsubsection{Results Matching with a requested profile}

Results presented in Figure 7 are obtained by applying this linear program. The production Pprod is completely similar to the demand (here the demand represents the power profile received from the negotiation module) as the relaxation factor is zero. The same power architecture is used as in the previous section. The load is variable between $100 \mathrm{~kW}$ and $400 \mathrm{~kW}$ in this case in order to exhibit large variations in the profile. The battery assures the smoothing of the day/night alternation and come back to the same level each $24 \mathrm{~h}$. The level of hydrogen is increasing from $300 \mathrm{~kg}$ to $400 \mathrm{~kg}$ in order to reach the target level fixed in Constraint (33).
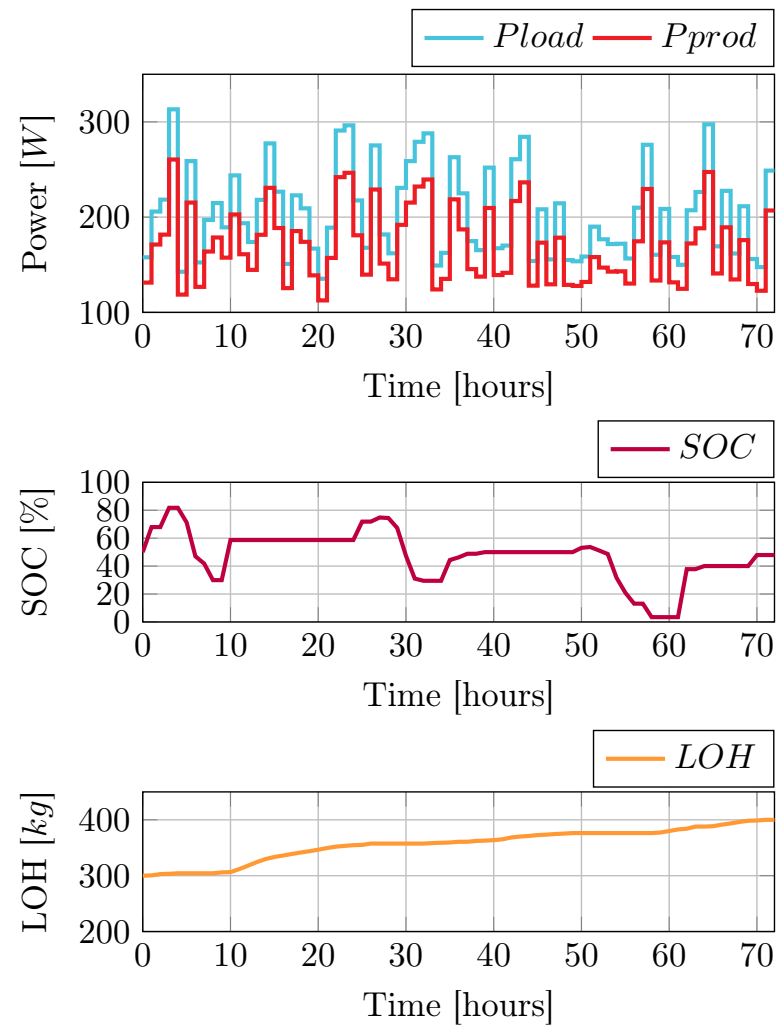

Figure 7 Management of the resources to match with a requested profile with $\alpha=0.168$

If one considers a $\alpha=0.168$, the results of the MILP are as showed in Figure 7. As we can see it, the profile generated Pprod is different from the provided one and respects the constraint given in $\mathrm{Eq}$ (37). In this case, one can see that the storage state of the battery varies all over the horizon in order to help the renewable production to fulfill the demand. The hydrogen level in- 
creases in order to reach the target fixed at the end of the horizon $\mathrm{LOH}_{K}=400 \mathrm{~kg}$.

\subsubsection{Results of source commitment}

Figure 8 shows the management of the different resources following the constraints explained in the previous sections. The power profile agreed on after the negotiation is designed with the best assignment of the sources and is completely equal to the load of the data center. Given the objective function, it can be noticed that the level of battery is varying all over the horizon in order to help the renewable production to fulfill the demand. Indeed, the level of hydrogen is increasing to maximize this objective at the end of the horizon. This choice can be justified by the difference of both storage device efficiencies.
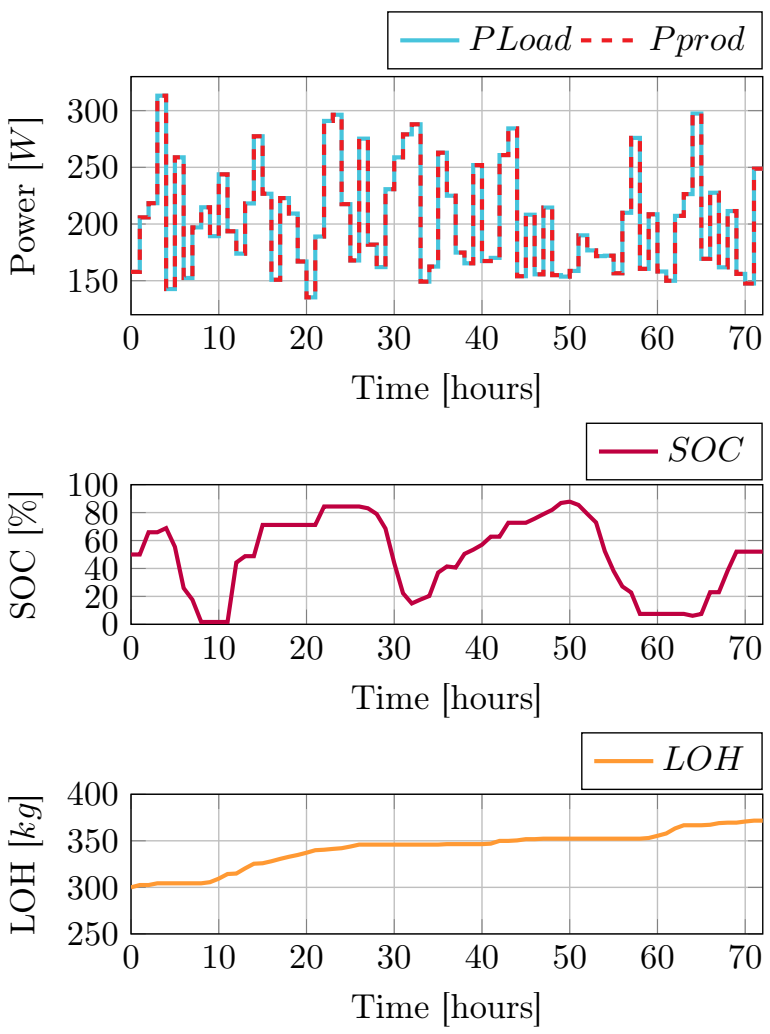

Figure 8 Source commitment results

\subsection{Summary of the results}

The results above suggest several interesting observations. First of all, the sizing of the electrical sources is very important as well as the values of the initial state of storage. They allow a good running of the programs. Otherwise, the management tool can provide an unfeasible model.
The MILP that matches with a given profile depends extremely of the relaxation factor. Sometimes, given the storage state at the moment of the negotiation and the energy production, the management tool provide an unfeasible model and is not capable to answer to the demand. The negotiation take action here and send a second profile with a different relaxation factor.

The execution time of the algorithms is at the scale of seconds which is compatible with the negotiation process as it's a synchronous negotiation.

The PDM is an efficient management tool of all energy sources (wind turbine, photovoltaics, batteries, fuel cells, electrolyzers) that is able to provide data center demand with $100 \%$ renewable energy.

Before concluding, we can mention that two negotiations in two different periods of the year converge to the same power profile to meet for supplying the data center. The two solutions, given after solving the two PDM power source commitment problems, have no reason to be the same. Indeed, these solutions do not only depend on the input power profile to address but also on the storage state and the target level of hydrogen at the end of the period.

\section{Conclusion}

In this paper, we presented (1) an analysis of the main trade offs involved in powering data centers with hybrid renewable energy system and the ANR DATAZERO project that aims to completely provide a data center with only renewable energy (2) a model of HRES composed of wind turbines, photovoltaic panels, batteries and hydrogen system (3) the problem statement defined by powering the demand of the data center with only renewable energy and the constraint satisfaction problem due to it (4) the linearization of the constraints in order to get a convenient usage of the sources and the mixed linear program which is used in the PDM (5) the power decision module which is a management tool able to manage a hybrid renewable energy system presenting four optimization problems depending on the stage of the negotiation. Additional constraints are also written to allow us to find appropriate solutions. These problems have been illustrated by several simulation. As the computation time is very short (less than $60 \mathrm{~s}$ ) considering the complexity of the problem, a negotiation step can be launched as soon as the power system notes a significant deviation from storage. We show that our optimal models are convenient to address the power commitment of a $100 \%$ renewable energy data center, since the resolution is obtained within few seconds. As 
future works, we plan to consider the aging of power sources in order to play maintenance scenarios similar to the real life one. For instance, one can manage in various manner one wind turbine or one battery depending on its degradation level so as to improve the sustainability of the power platform.

\section{Acknowledgments}

This work was supported in part by the ANR DATAZERO (contract "ANR-15-CE25-0012") project and by the EIPHI Graduate school (contract "ANR-17-EURE-0002"). We also thank Mr. Damien Landré for testing our MILP implementation efficiently during his Master thesis.

\section{References}

1. Aksanli, B., Venkatesh, J., Zhang, L., Rosing, T.: Utilizing green energy prediction to schedule mixed batch and service jobs in data centers. In: Proceedings of the 4th Workshop on Power-Aware Computing and Systems, p. 5. ACM (2011)

2. Apple: Apple facilities, environmental footprint report. Apple and the Environment (2013). URL http: //www . apple.com/environment/

3. Arlitt, M., Bash, C., Blagodurov, S., Chen, Y., Christian, T., Gmach, D., Hyser, C., Kumari, N., Liu, Z., Marwah, M., et al.: Towards the design and operation of net-zero energy data centers. In: Thermal and Thermomechanical Phenomena in Electronic Systems (ITherm), 2012 13th IEEE Intersociety Conference on, pp. 552-561. IEEE (2012)

4. Bajpai, P., Dash, V.: Hybrid renewable energy systems for power generation in stand-alone applications: A review. Renewable and Sustainable Energy Reviews 16(5), 2926-2939 (2012)

5. Caux, S., Rostirolla, G., Stolf, P.: Smart Datacenter Electrical Load Model for Renewable Sources Management. In: International Conference on Renewable Energies and Power Quality (ICREPQ), Salamanca, Spain, 21/03/2018-23/03/2018, vol. 16, p. (on line). European Association for the Development of Renewable Energies, Environment and Power Quality, http://www.icrepq.com (2018). URL http://www. icrepq. com/icrepq18/ 231-18-caux.pdf

6. Cook, G., Lee, J., Tsai, T., Kong, A., Deans, J., Johnson, B., Jardim, E.: Clicking clean: Who is winning the race to build a green internet? Greenpeace Inc., Washington, DC (2017)

7. ANR DATAZERO project (2015-2019). http:// datazero.org
8. Deng, W., Liu, F., Jin, H., Liao, X.: Online control of datacenter power supply under uncertain demand and renewable energy. In: Communications (ICC), 2013 IEEE International Conference on, pp. 4228-4232. IEEE (2013)

9. Fingersh, L., Simms, D., Hand, M., Jager, D., Cotrell, J., Robinson, M., Schreck, S., Larwood, S.M.: Wind tunnel testing of NREL's unsteady aerodynamics experiment. In: 20th ASME Wind Energy Symposium (2001). DOI https://doi.org/ 10.2514/6.2001-35

10. Goiri, Í., Beauchea, R., Le, K., Nguyen, T.D., Haque, M.E., Guitart, J., Torres, J., Bianchini, R.: Greenslot: scheduling energy consumption in green datacenters. In: High Performance Computing, Networking, Storage and Analysis (SC), 2011 International Conference for, pp. 1-11. IEEE (2011)

11. Goiri, I., Haque, M.E., Le, K., Beauchea, R., Nguyen, T.D., Guitart, J., Torres, J., Bianchini, R.: Matching renewable energy supply and demand in green datacenters. Ad Hoc Networks 25, 520-534 (2015)

12. Goiri, I.n., Katsak, W., Le, K., Nguyen, T.D., Bianchini, R.: Parasol and greenswitch: Managing datacenters powered by renewable energy. SIGARCH Comput. Archit. News 41(1), 51-64 (2013). DOI 10.1145/2490301.2451123. URL http://doi.acm. org/10.1145/2490301.2451123

13. Govindan, S., Sivasubramaniam, A., Urgaonkar, B.: Benefits and limitations of tapping into stored energy for datacenters. In: Computer Architecture (ISCA), 2011 38th Annual International Symposium on, pp. 341-351. IEEE (2011)

14. Govindan, S., Wang, D., Sivasubramaniam, A., Urgaonkar, B.: Leveraging stored energy for handling power emergencies in aggressively provisioned datacenters. In: ACM SIGARCH Computer Architecture News, vol. 40(1), pp. 75-86. ACM (2012)

15. Gurobi Optimization, I.: Gurobi optimizer reference manual (2016). URL http://www.gurobi. com

16. Hackenberg, D., Schöne, R., Ilsche, T., Molka, D., Schuchart, J., Geyer, R.: An energy efficiency feature survey of the intel haswell processor. In: International Parallel and Distributed Processing Symposium Workshop (IPDPSW), pp. 896-904. IEEE (2015)

17. Haddad, M., Da Costa, G., Nicod, J.M., Péra, M.C., Pierson, J.M., Rehn-Sonigo, V., Stolf, P., Varnier, C.: Combined it and power supply infrastructure sizing for standalone green data centers. Sustainable Computing: Informatics and Systems p. 100505 (2021). URL https://doi.org/ 
$10.1016 / \mathrm{j}$. suscom. 2020.100505

18. Haddad, M., Nicod, J.M., Boubacar Mainassara, Y., Rabehasaina, L., Al Masry, Z., Péra, M.C.: Wind and solar forecasting for renewable energy system using sarima-based model. In: 6th International conference on Time Series and Forecasting ( 2019). Gran Canaria, Spain (2019). URL https://publiweb.femto-st.fr/ tntnet/entries/16409/documents/author/data

19. Haddad, M., Nicod, J.M., Péra, M.C.: data-center supply-refueling station synergy. In: Vehicle Power and Propulsion Conference (VPPC 2017), pp. 1 6. IEEE, Belfort (2017)

20. Haddad, M., Nicod, J.M., Varnier, C., Peéra, M.C.: Mixed integer linear programming approach to optimize the hybrid renewable energy system management for supplying a stand-alone data center. In: 2019 Tenth International Green and Sustainable Computing Conference (IGSC), pp. 1-8. IEEE (2019)

21. Hofmann, J., Fey, D., Eitzinger, J., Hager, G., Wellein, G.: Analysis of intel's haswell microarchitecture using the ecm model and microbenchmarks. In: International Conference on Architecture of Computing Systems, pp. 210-222. Springer (2016)

22. Kassab, A., Nicod, J.M., Philippe, L., Rehn-Sonigo, V.: Scheduling independent tasks in parallel under power constraints. In: 46th International Conference on Parallel Processing (ICPP), pp. 543-552. Bristol, UK (2017). DOI 10.1109/ICPP.2017.63

23. Katz, R.H.: Tech titans building boom. IEEE spectrum 46(2), 40-54 (2009)

24. Kaur, T., Chana, I.: Energy efficiency techniques in cloud computing: A survey and taxonomy. ACM Computing Surveys (CSUR) 48(2), 22 (2015)

25. Kontorinis, V., Zhang, L.E., Aksanli, B., Sampson, J., Homayoun, H., Pettis, E., Tullsen, D.M., Rosing, T.S.: Managing distributed ups energy for effective power capping in data centers. In: Computer Architecture (ISCA), 2012 39th Annual International Symposium on, pp. 488-499. IEEE (2012)

26. Koomey, J.: Growth in data center electricity use 2005 to 2010. A report by Analytical Press, completed at the request of The New York Times 9 (2011)

27. Lei, H., Zhang, T., Liu, Y., Zha, Y., Zhu, X.: Sgeess: Smart green energy-efficient scheduling strategy with dynamic electricity price for data center. Journal of Systems and Software 108, 23-38 (2015)

28. Li, C., Wang, R., Li, T., Qian, D., Yuan, J.: Managing green datacenters powered by hybrid renewable energy systems. In: The 11th International
Conference on Autonomic Computing, pp. 261-272. USENIX (2014)

29. Li, J., Li, Z., Ren, K., Liu, X.: Towards optimal electric demand management for internet data centers. IEEE Transactions on Smart Grid 3(1), 183192 (2012)

30. Liu, Z., Chen, Y., Bash, C., Wierman, A., Gmach, D., Wang, Z., Marwah, M., Hyser, C.: Renewable and cooling aware workload management for sustainable data centers. In: ACM SIGMETRICS Performance Evaluation Review, vol. 40(1), pp. 175186. ACM (2012)

31. Miller, R.: Huge solar array will support nj data center. datacenterknowledge (2011). http://www.datacenterknowledge. com/archives/2011/06/14/

huge-solar-array-will-support-nj-data-center/

32. Orgerie, A.C., Assuncao, M.D.d., Lefevre, L.: A survey on techniques for improving the energy efficiency of large-scale distributed systems. ACM Comput. Surv. 46(4), 47:1-47:31 (2014). DOI 10.1145/2532637. URL http://doi.acm.org/10. $1145 / 2532637$

33. Oró, E., Depoorter, V., Garcia, A., Salom, J.: Energy efficiency and renewable energy integration in data centres. strategies and modelling review. Renewable and Sustainable Energy Reviews 42, 429 445 (2015)

34. Pierson, J.M., Baudic, G., Caux, S., Celik, B., Da Costa, G., Grange, L., Haddad, M., Lecuivre, J., Nicod, J.M., Philippe, L., Rehn-Sonigo, V., Roche, R., Rostirolla, G., Sayah, A., Stolf, P., Thi, M.T., Varnier, C.: DATAZERO: DATAcenter with Zero Emission and RObust management using renewable energy. IEEE Access 7, (on line) (2019). URL http://doi.org/10.1109/ACCESS. 2019.2930368

35. Sengupta, M., Xie, Y., Lopez, A., Habte, A., Maclaurin, G., Shelby, J.: The national solar radiation data base (NSRDB). Renewable and Sustainable Energy Reviews 89, 51-60 (2018)

36. Sheme, E., Stolf, P., Da Costa, G., Pierson, J.M., Frashëri, N.: Efficient energy sources scheduling in green powered datacenters: A cloudsim implementation. NESUS workshop (2016)

37. Stolf, P., Borgetto, D., Aubert, M.: Host management policy for energy efficient dynamic allocation. In: 2016 Seventh International Green and Sustainable Computing Conference (IGSC), pp. 17. Hangzhou, China (2016). DOI 10.1109/IGCC. 2016.7892622

38. Thi, M.T., Pierson, J.M., Da Costa, G., Stolf, P., Nicod, J.M., Rostirolla, G., Haddad, M.: Negotiation game for joint it and energy management in 
green datacenters. Future Generation Computer Systems 110, 1116-1138 (2020)

39. Thibodeau, P.: Wind power data center project planned in urban area. ComputerWorld, Apr (2008)

40. Uddin, M., Rahman, A.A., Shah, A.: Criteria to select energy efficiency metrics to measure performance of data centre. International Journal of Energy Technology and Policy 8(3-6), 224-237 (2012)

41. Uddin, M., Shah, A., Alsaqour, R.: Implementation of virtualization in data centers to increase proficiency and performance. Journal of Theoretical \& Applied Information Technology 53(2) (2013)

42. Urgaonkar, R., Urgaonkar, B., Neely, M.J., Sivasubramaniam, A.: Optimal power cost management using stored energy in data centers. In: Proceedings of the ACM SIGMETRICS joint international conference on Measurement and modeling of computer systems, pp. 221-232. ACM (2011)

43. Villebonnet, V., Da Costa, G., Lefèvre, L., Pierson, J.M., Stolf, P.: Energy aware dynamic provisioning for heterogeneous data centers. In: 2016 28th International Symposium on Computer Architecture and High Performance Computing (SBAC-PAD), pp. 206-213. IEEE (2016)

44. Wang, D., Ren, C., Sivasubramaniam, A., Urgaonkar, B., Fathy, H.: Energy storage in datacenters: what, where, and how much? In: ACM SIGMETRICS Performance Evaluation Review, vol. 40(1), pp. 187-198. ACM (2012)

\section{Appendices}

The range of the variables used in the four following MILPs are defined as follow:

- Pch ${ }_{k}, P d c h_{k}, P e z_{k}, P c h_{k}^{\prime}, P d c h_{k}^{\prime}, P e z_{k}^{\prime}, Q e z_{k}, Q f c_{k}$, $Q e z_{k}^{\prime}, Q f c_{k}^{\prime}, P f c_{k}, P e z_{k}$ are defined $\forall k \in \llbracket 0, K-1 \rrbracket$,

$-x_{k}, y_{k}, z_{k}, u_{k}, v_{k}$ are defined $\forall k \in \llbracket 0, K-1 \rrbracket$,

- $S O C_{k}, L O H_{k}$ are defined $\forall k \in \llbracket 0, K \rrbracket$.

\section{A Providing a constant power profile}

The obtained model used to provide a constant power profile as a first proposition for the negotiation is:
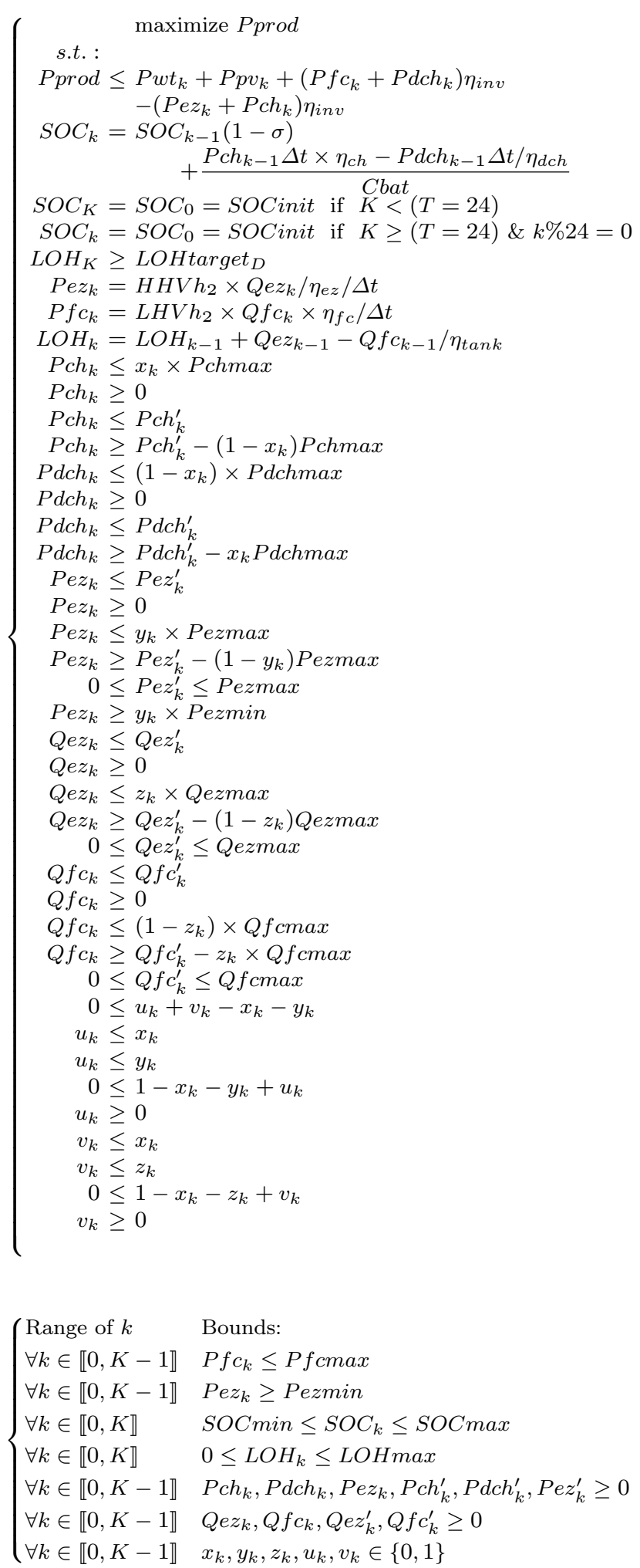


\section{B Providing a non constant power profile}

The obtained model used to provide a non constant power profile as a proposition for the negotiation is:

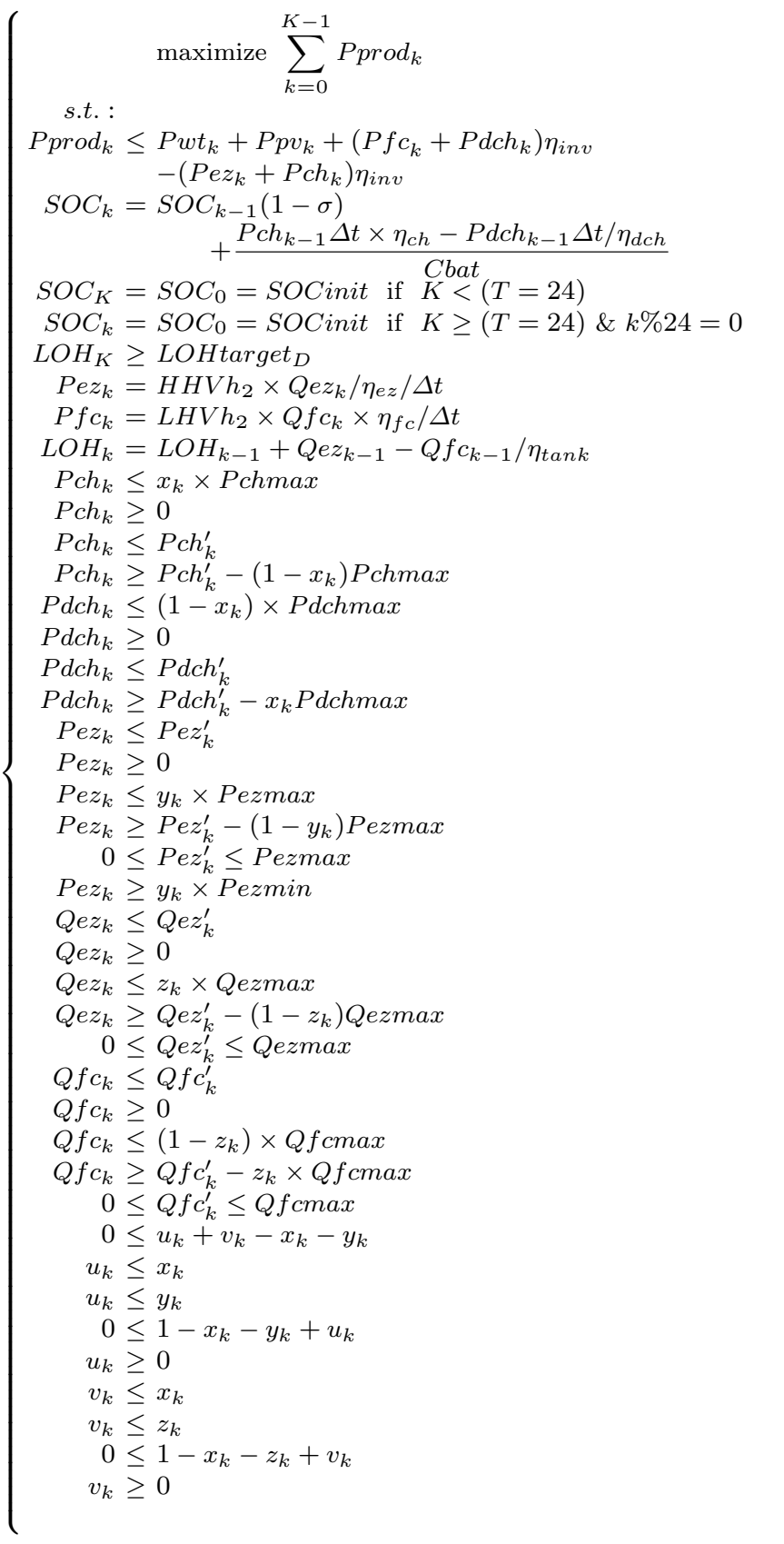

\section{Matching with a requested profile}

The model used to provide a power profile that can match with a profile received from the negotiation is:

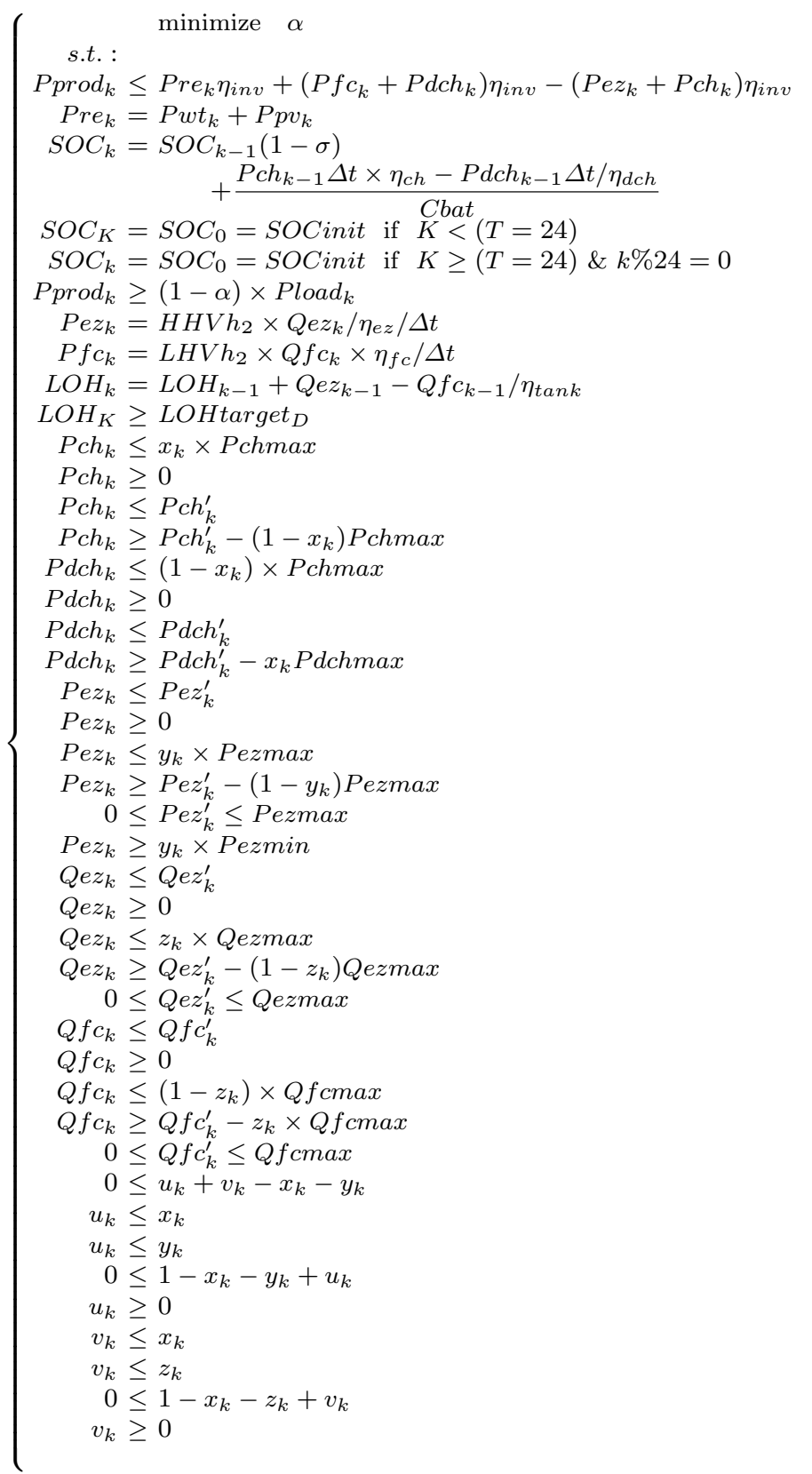

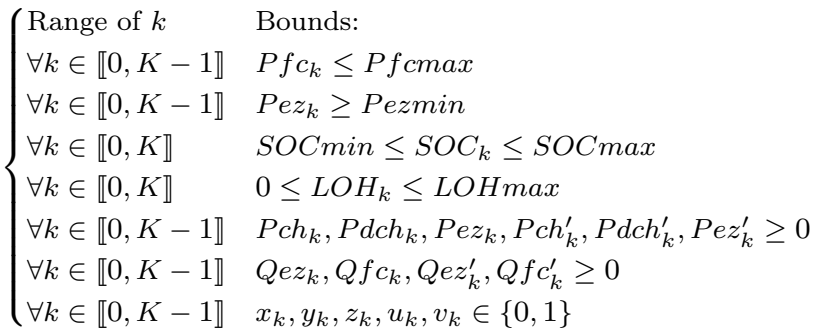

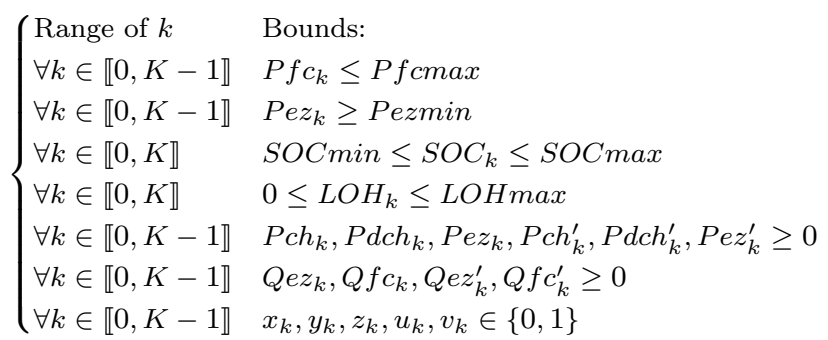




\section{Source commitment}

The obtained model used for the source commitment is defined as follow:
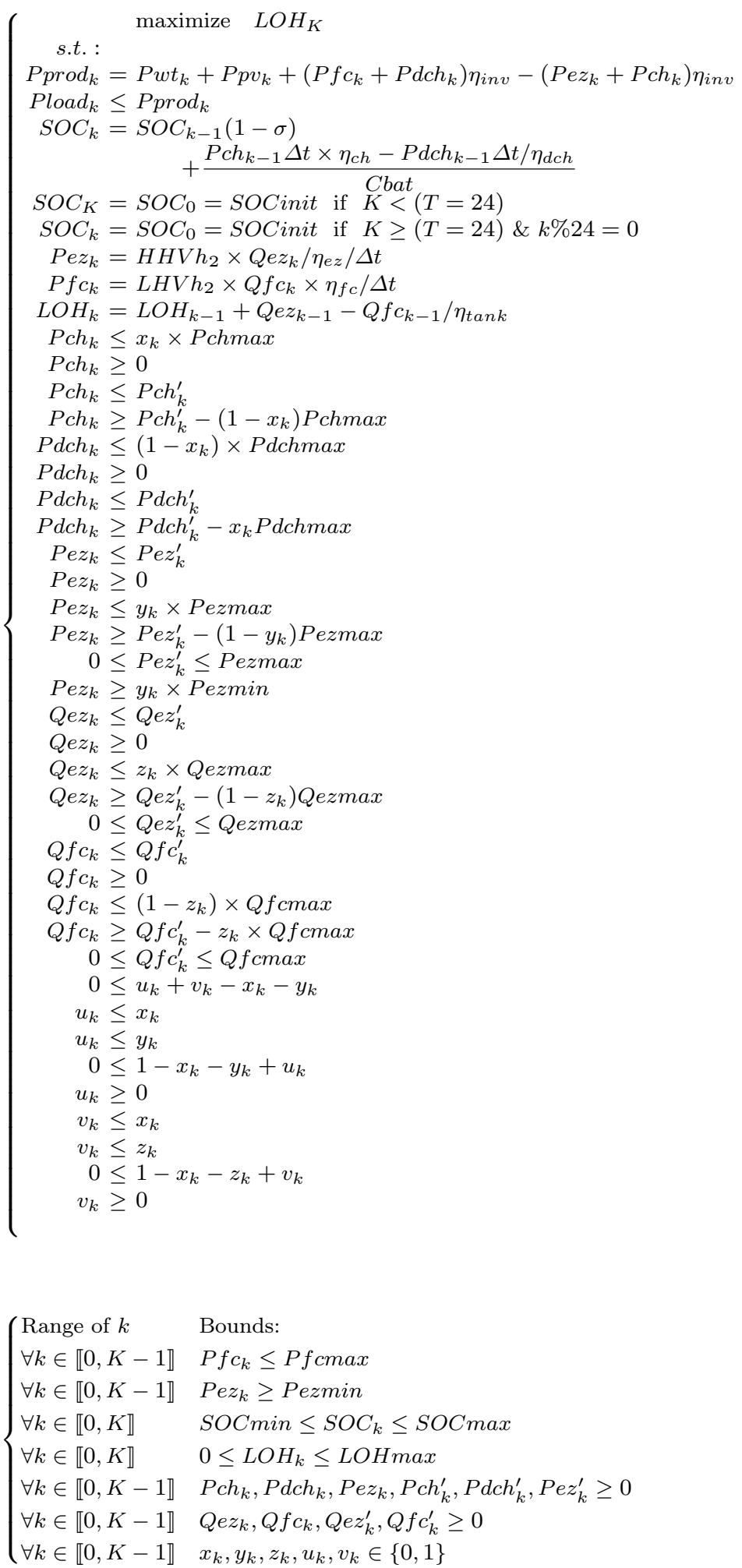